\title{
Vapor and Liquid Equilibria in Porous Media
}

by

Youn-Ok Shin

Department of Chemical Engineering

McGill University, Montreal

March, 1999

A thesis submitted to the Faculty of Graduate Studies and Research in partial fulfillment of the requirements for the degree of Master of Engineering,

- Youn-Ok Shin, 1999. 
National Library

of Canada

Acquisitions and

Bibliographic Senvices

395 Wellington Street

Ottawa ON K1A ON4

Canada
Bibliothèque nationale du Canada

Acquisitions et services bibliographiques

395. ne Wellington Otawa ON KIA ONA Canada
The author has granted a nonexclusive licence allowing the National Library of Canada to reproduce, loan, distribute or sell copies of this thesis in microform, paper or electronic formats.

The author retains ownership of the copyright in this thesis. Neither the thesis nor substantial extracts from it may be printed or otherwise reproduced without the author's permission.
L'auteur a accordé une licence non exclusive permettant à la Bibliothèque nationale du Canada de reproduire, prêter, distribuer ou vendre des copies de cette thèse sous la forme de microfiche/film, de reproduction sur papier ou sur format électronique.

L'auteur conserve la propriété du droit d'auteur qui protège cette thèse. $\mathrm{Ni}$ la thèse ni des extraits substantiels de celle-ci ne doivent être imprimés ou autrement reproduits sans son autorisation. 


\section{ABSTRACT}

The alteration of the vapor and liquid equilibrium (VLE) of volatile organic mixtures by using porous media at the liquid-vapor interface was studied. Kelvin, assuming ideal behavior of fluids, first introduced the vapor pressure of liquid over a meniscus as a function of its surface tension and the radius of the curvature. A thermodynamic model $\left(\mathrm{SS}_{\bmod }\right.$ model) predicting the VLE of non-ideal organic mixtures in porous media was developed as a function of pore sizes based on the pressure equations available in literature. The model was used to predict the VLE of two aqueous alcohol solutions, ethanol-water and propanol-water, and two binary alcohol solutions, methanolisopropanol and ethanol-octane. Experiments were conducted using sintered metal and fritted glass plates as porous media and compared with the model predictions. The model predictions for the actual pore diameters tested showed good agreement with the experimental results. 


\section{RÉSUMÉ}

Ce mémoire porte sur la modification de l'équilibre liquide-vapeur (ELV) de mélanges organiques volatils par l'utilisation de milieux poreux à l'interface liquidevapeur. C'est Kelvin qui, pour des comportements présumés idéaux, a le premier démontré que la pression de vapeur d'un liquide par rapport à un ménisque est fonction de la tension superficielle du liquide et du rayon de courbure du ménisque. On a formulé, en fonction de la taille des pores et à partir des équations de pression disponibles dans les publications, un modèle thermodynamique (modèle $\mathrm{SS}_{\mathrm{mod}}$ ) pour prédire l'ELV de mélanges organiques non idéales dans des milieux poreux. Ce modèle a été utilisé pour prédire l'ELV de deux solutions binaires d'alcool (méthanol-isopropanol et éthanoloctane). Les résultats des expériences menées sur des plaques de métal et de verre frittés ont été comparés aux prévisions du modèle. Celles-ci cadrent bien avec les résultats des expériences pour ce qui est des diamètres de pore réels. 


\section{ACKNOWLEDGMENTS}

I would like to express special thanks to my supervisor Dr. Jana Simandl who encouraged me in every way possible. The assistance of Danielle Béland from Varian in operating the autosampler and the gas chromatograph is truly appreciated. I would also like to thank Dr. M.E. Weber, Dr. J.H Vera and the research group members for their recommendations and suggestions. The financial support of the Natural Sciences and Engineering Research Council (NSERC), the department of Chemical Engineering at McGill University and the Brace Research Institute is greatly acknowledged. 


\section{TABLE OF CONTENTS}

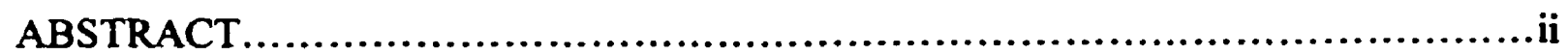

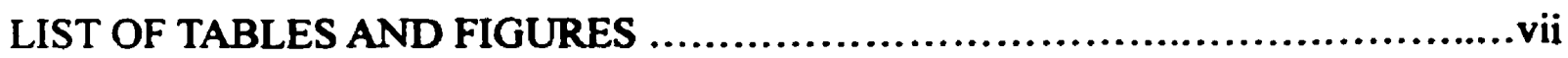

1.0 INTRODUCTION............................................................

2.0 BACKGROUND THEORIES AND THE SS $_{\bmod }$ MODEL $\ldots \ldots \ldots \ldots \ldots \ldots \ldots \ldots \ldots . . . . . \ldots$

2.1 Kelvin Equation...................................................6

2.2 Yeh Equation......................................................

2.3 Shapiro and Stenby Equations.........................................8

2.4 Developmenet of the SS $_{\bmod }$ Model and Computational Procedures..........11

3.0 EXPERIMENTAL APPARATUS AND PROCEDURES $\ldots \ldots \ldots \ldots \ldots \ldots \ldots \ldots \ldots . . \ldots \ldots$

3.1 Experimental Apparatus........................................... 15

3.1.1 Vials and Porous Media..................................... 15

3.1.2 Headspace Autosampler...................................16

3.1.3 Gas Chromatograph (GC) ................................ 19

3.2 Experimental Procedures..........................................22

3.2.1 Determination of Equilibrium Time...........................22

3.2.2 Response Factors (K factors) for Non-Aqueous Systems..........24

3.2.3 Response Factors for Aqueous Systems.......................26

3.2.4 Determination of Liquid Volume in the Vials.....................30

4.0 RESULTS AND DISCUSSION.............................................

4.1 VLE in Porous Media as Function of Pore Sizes ...........................32

4.2 Model Predictions for Aqueous and Non-Aqueous Systems................34

4.3 Actual Pore Sizes of the Porous Media. .................................37

4.4 Comparison of Model Predictions with Experimental Results...............43

5.0 CONCLUSIONS AND RECOMMENDATIONS ...............................49

6.0 NOMENCLATURE.......................................................... 51

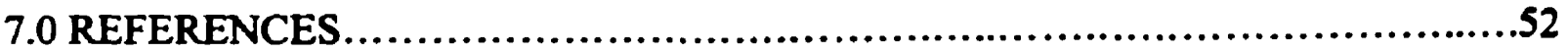


APPENDIX A: List of Equations.............................................55

APPENDIX B: SS $_{\bmod }$ Model Program.................................................61

APPENDIX C: Vapor Phase Analyses Calculated by Two Different Methods............67

APPENDIX D: Experimental Data.............................................69 


\section{LIST OF TABLES AND FIGURES}

\section{TABLES}

1.1 Summary of Binary Systems Tested Experimentally at McGill University...........4

3.1 Summary of Porous Plate Specifications......................................16

3.2 Summary of Autosampler Parameters........................................19

3.3 Summary of Gas Chromatography Parameters...............................21

3.4 Mole Fraction of Methanol in Isopropanol as a Function of Liquid Volume.........31

4.1 Stated Nominal and Measured Pore Sizes (Wong, 1997) .......................41

\section{FIGURES}

2.1 Schematic of a Vapor and Liquid Interface in Porous Media....................6

3.1 Schematic (not drawn to scale) of VLE Analysis............................14

3.2 Schematic (not drawn to scale) of Glass Vials............................... 15

3.3 Schematic (not drawn to scale) of Headspace Autosampler.................... 16

3.4 Schematic of Loop Fill Mode (Varian, 1991) ...............................18

3.5 Schematic of Inject Mode (Varian, 1991) ..................................18

3.6 Schematic (not drawn to scale) of GC (McNair and Miller, 1997)................20

3.7 Minimum Equilibrium Time for 60 mol\% MeOH Solution.......................23

3.8 Determination of Response Factor for Methanol .............................25

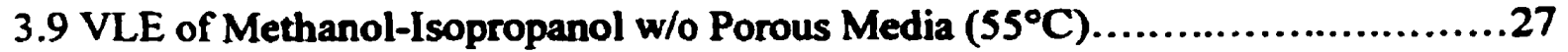


3.10 VLE of Ethanol-n-Octane w/o Porous Media $\left(75^{\circ} \mathrm{C}\right) \ldots \ldots \ldots \ldots \ldots \ldots \ldots \ldots \ldots . . .28$

3.11 Calibration of Peak Area to Mole Fraction of Ethanol in Water ...................29

4.1 Percent Increase in Vapor Mole Fraction as Function of Pore Sizes .................33

4.2 Model Prediction for VLE of Ethanol-Water Mixtures at $60^{\circ} \mathrm{C} \ldots \ldots \ldots \ldots \ldots \ldots . . . . . .35$

4.3 Model Prediction for VLE of Propanol-Water Mixtures at $60^{\circ} \mathrm{C}$...................36

4.4 Model Prediction for VLE of Methanol-Isopropanol Mixtures at $55^{\circ} \mathrm{C} \ldots \ldots \ldots \ldots . . . .38$

4.5 Model Prediction for VLE of Ethanol-n-Octane Mixtures at $75^{\circ} \mathrm{C} \ldots \ldots \ldots \ldots \ldots . . . . . . .39$

4.6 SEM of 40 $4 \mathrm{~m}$ Sintered Metal Plate Surface (Wong, 1997)......................40

4.7 SEM of 4-8 $\mu \mathrm{m}$ Fritted Glass Plate Surface (Wong, 1997) .........................40

4.8 Schematic of Cross-Section of $4-8 \mu \mathrm{m}$ Fritted Glass Plate.......................41

4.9 Schematic of Contact Angles in Different Shapes of Porous Media.................42

4.10 VLE of Ethanol-Water at $60^{\circ} \mathrm{C}$ in Sintered Metal Plate .........................44

4.11 VLE of Ethanol-Water at $60^{\circ} \mathrm{C}$ in Fritted Glass Plate ...........................45

4.12 VLE of Propanol-Water at $60^{\circ} \mathrm{C}$ in Fritted Glass Plate..........................46

4.13 VLE of Mthanol-Isopropanol at $55^{\circ} \mathrm{C}$ in Fritted Glass Plate......................47

4.14 VLE of Ethanol-n-Octane at $75^{\circ} \mathrm{C}$ in Fritted Glass Plate.........................48 


\subsection{INTRODUCTION}

The alteration of the vapor and liquid equilibria (VLE) of volatile organic compounds is of interest since it could allow the separation of organic mixtures that are difficult to distil. When a porous medium is located at the liquid-vapor interface, the liquid surface forms a meniscus due to its tendency to minimize surface energy (Atkins, 1982). The capillary pressure existing at the interface results in a pressure difference between the liquid and the vapor. As a result, the vapor and liquid equilibrium in porous media differs from that established over a flat liquid-vapor interface.

The vapor pressures in porous media have been studied extensively since Kelvin (Defay, 1966). He first proposed that the vapor pressure over a meniscus is a function of the liquid surface tension and the radius of the curvature. The Kelvin equation was developed assuming that the vapor and liquid phases behave ideally and that the curvature at the liquid interface is a fraction of a sphere. However, the experimental results available in literature show that the vapor pressures measured experimentally are orders of magnitude smaller than the values predicted by the Kelvin equation. Yeh et al. (1991b) modified the Kelvin equation to include the liquid surface tension in porous media by estimating the dispersion and polar interactions at the solid-liquid interface. Shapiro and Stenby (1997) introduced a new form of Kelvin equation that includes the non-ideality of the fluids, which cannot be ignored for oil-gas-reservoirs at high pressures.

In addition to the thermodynamic approaches, experimental results examining the VLE in porous media have been published in literature. Yeh et al. (1991a) tested the VLE of 72 binary systems including ethanol-water and propanol-water mixtures using sintered 
metal plates with pore sizes ranging from 2.8 to 280 microns. Their results showed a significant increase in the alcohol concentration in the vapor phase for both ethanol-water and propanol-water mixtures. Wong (1997) also studied the VLE of ethanol-water and propanol-water mixtures at McGill University. Her experiments were conducted by using sintered metal, fritted glass plates and Durapore membranes with pore sizes ranging from 0.45 to 40 microns. Her results showed that, at equilibrium, the alcohol concentrations in the vapor phase increased by $4-6 \%$ when the porous media were placed at the liquidvapor interface.

The objective of this Master's thesis was to extend the study of the VLE in porous media in terms of the thermodynamics and the experiments. A mathematical model, the $\mathrm{SS}_{\text {mod }}$ model, which predicts the VLE in porous media as a function of pore sizes, was developed based on the pressure equations suggested by Shapiro and Stenby (1997). The model was used to predict the VLE of previously studied aqueous alcohol mixtures, ethanol-water and propanol-water, and the VLE of two new binary systems, methanolisopropanol and ethanol-n-octane at 40 and 5 micron pore sizes. The model predictions were compared with the experimental results obtained from this work as well as Wong's data. The experimental results published by Yeh et al. (1991a) were not used in the comparison due to ambiguities in their plate pore sizes and the experimental apparatus.

The experiments were conducted using a Genesis headspace autosampler and a Varian gas chromatograph (GC) combined with the glass vials containing porous media. This apparatus was first used in Wong's experiments. The experimental resuits of the VLE of methanol-isopropanol and ethanol-n-octane measured without porous media were compared with the literature values (Gmehling, (1981)) and showed excellent agreement. 
This result indicates that the experimental technique used in the analyses provided precise and reproducible data.

In this study, sintered metal plates with nominal pore size of 40 microns and fritted glass plates with nominal pore size of 4-8 microns were used as porous media. The VLE of ethanol-water with sintered metal plates obtained in Wong's experiments (1997) was reproduced in order to test the experimental techniques. The results were also compared with the model predictions. With the same porous medium, the VLE of new systems, methanol-isopropanol and ethanol-n-octane, were measured. One advantage of using binary alcohol systems as opposed to aqueous alcohol systems is that all compounds can be detected by the GC. For the ethanol-water and propanol-water systems at this pore size, Wong's experimental results were used for the comparison with the model. A summary of binary systems tested with the McGill apparatus and compared with the $\mathrm{SS}_{\bmod }$ model predictions is given in Table 1.1.

The model-predicted VLE of aqueous alcohol solutions indicated that the alcohol concentration in the vapor phase should increase by $6-7 \%$ in 40 micron pores and $50-60 \%$ in 5 micron pores. For methanol-isopropanol and ethanol-n-octane solutions, less pronounced changes in the VLE in porous media were predicted: only $5-6 \%$ increase in the vapor phase mole fraction of the more volatile compound in 5 micron pores. These model predictions were compared with the experimental values and showed good agreement.

Chapter 2 of this thesis summarizes the background information of the thermodynamics of the VLE in porous media suggested by Kelvin, Yeh et al. and Shapiro and Stenby. This chapter also includes the development of the $\mathrm{SS}_{\bmod }$ model as well as the 
computational procedures. The experimental apparatus and procedures are presented in Chapter 3. The $S_{\text {mod }}$ model predictions of the VLE as a function of pore sizes are discussed and compared with the experimental results in Chapter 4. Conclusions and recommendations stemming from this work are summarized Chapter 5.

Table 1.1: Summary of Binary Systems Tested Experimentally at McGill University

\begin{tabular}{|c|c|c|c|c|}
\hline & ethanol-water & Propanol-water & $\begin{array}{l}\text { methanol- } \\
\text { isopropanol }\end{array}$ & ethanol-n-octane \\
\hline Plane surface & $\begin{array}{c}\text { Wong (1997) \& } \\
\text { Shin }\end{array}$ & Wong (1997) & Shin & Shin \\
\hline $\begin{array}{c}40 \mu \mathrm{m} \text { sintered } \\
\text { metal (nominal) }\end{array}$ & $\begin{array}{c}\text { Wong (1997) \& } \\
\text { Shin }\end{array}$ & - & - & - \\
\hline $\begin{array}{c}4-8 \mu \mathrm{m} \text { fritted } \\
\text { glass (nominal) }\end{array}$ & Wong (1997) & Wong (1997) & Shin & Shin \\
\hline \begin{tabular}{c} 
Temperature \\
\hline
\end{tabular} & $60^{\circ} \mathrm{C}$ & $60^{\circ} \mathrm{C}$ & $55^{\circ} \mathrm{C}$ & $75^{\circ} \mathrm{C}$ \\
\hline
\end{tabular}




\subsection{BACKGROUND THEORIES AND THE SS mod MODEL}

The thermodynamics of vapor-liquid equilibria in porous media were first introduced by Kelvin (Defay, (1960)). Since then, many attempts have been made either to modify or to develop a new vapor pressure equation better suited for non-ideal mixtures. Yeh et al. (1991b) modified the Kelvin equation to include the properties of the liquid in the pores that are different from the properties of the bulk solution. Boucher (1984) developed an equation to predict the vapor pressure in porous media under the gravitational field. Kuz (1991) proposed a general vapor pressure equation, which relates the chemical potential and the surface tension of the solution. Shapiro and Stenby (1997) introduced a new form of the Kelvin equation to include the non-ideality of the fluid in terms of its compressibility factor.

In contrast to those thermodynamic approaches, Truong and Wayner (1987) studied physical factors acting on the solid and liquid interface. Because of the wetting behavior of the liquid on the solid surface, the chemical potential in a thin film differs from that of a bulk liquid resulting in the excess potential attributed to van der Waals' dispersion force. Yeh et al (1991b) argued that not only the dispersion force but the polar interactions in the solid and liquid interface play an important role in altering the vapor pressure of the mixture in porous media.

In this chapter, the Kelvin, Yeh $e t$ al. and Shapiro and Stenby equations are summarized in Sections 2.1 to 2.3. The development of the $\mathrm{SS}_{\bmod }$ model and the computational procedures are presented in Section 2.4. 


\section{$2.1 \mathrm{Kelvin}$ Equation}

Kelvin first developed an equation for the vapor pressure of solutions in porous media, i.e., capillaries, as a function of surface tension and the radius of curvature (Figure 2.1). The Kelvin equation was developed by assuming that the work done by the liquid to go from the vapor pressure over a flat to a curved liquid-vapor interface is equal to the change in its surface energy, called surface tension (Atkins, 1982). The assumptions were

i. vapor and liquid have single component behaviors (i.e. ideal system)

ii. the liquid is incompressible

iii. the curved surface at the vapor-liquid interface is a fraction of a sphere.

Thus, the vapor pressure in porous media can be written as

$$
\ln \left(\frac{P_{v, \text { avo }}}{P_{v, 0}}\right)=-2 \sigma \frac{V_{L}}{r_{c o v v} R T}
$$

where $\sigma$ is the normal surface tension of bulk solution, $P_{v, \text { curv }}$ and $P_{v, o}$ are vapor pressures of the solution over a curved and a flat liquid-vapor interface respectively. $V_{L}$ is liquid molar volume, $r_{\text {curv }}$ is the radius of the curvature, $R$ is the universal gas constant, and $T$ is the absolute temperature of the liquid (Defay, (1966)).

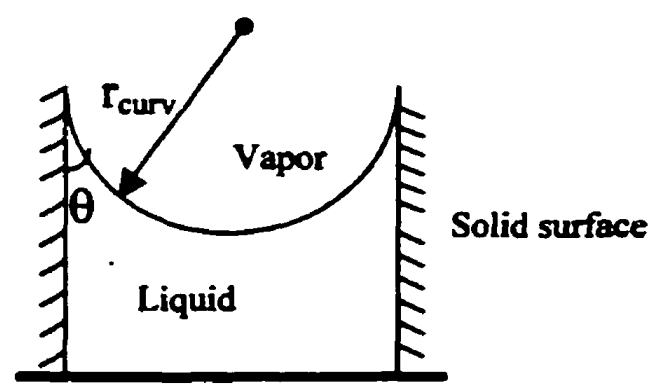

Figure 2.1: Schematic of a Vapor and Liquid Interface in Porous Media 


\subsection{Yeh Equation}

Yeh et al. (1991a) conducted experiments examining vapor pressures of 72 different organic mixtures and found that the vapor pressures in their porous media were orders of magnitude lower than the ones predicted by the Kelvin equation. They introduced the importance of the dispersion interactions and the polar interactions at the solid-liquid interface. The original Kelvin equation was modified to accommodate the surface tension in porous media that differs from the normal surface tension (Yeh et al., 1991b). The reduced vapor pressure of a liquid $P_{v r}$ can be defined as

$$
\ln P_{v r}=k\left(1-1 / T_{r}\right)
$$

and the surface tension of liquid is defined as

$$
\sigma_{L}=A\left(1-T_{r}\right)^{B}
$$

where $T_{r}$ is reduced temperature, and $A, B$ and $k$ are constants. Substitution of equation 2.2.1 into equation 2.2 .2 yields

$$
P_{v r}=-(k / A) \sigma_{L} / T_{r}
$$

Thus, at constant temperature, the change in vapor pressure from flat to curved liquidvapor interface can be written as

$$
\ln \left(P_{V r_{\text {cur }}}\right)=\left(\frac{\sigma_{L, c u r v}}{\sigma_{L, 0}}\right) \ln \left(P_{v r_{0}}\right)
$$

$P_{\mathrm{v}, \mathrm{O}}$ is the reduced vapor pressure, and $\sigma_{\mathrm{L}, \mathrm{O}}$ is the surface tension of the bulk solution without porous media. $P_{v r, c u r v}$ and $\sigma_{L, \text { curv }}$ are the reduced vapor pressure and the surface tension of the solution in porous media respectively. 
The surface tension of the liquid in porous media, $\sigma_{L_{\text {curv }}}$ is calculated by

$$
\sigma_{L, c u r v}=\sigma_{L, 0}+\frac{1}{4}\left(F_{d i s}+F_{p o l}\right)
$$

$F_{\text {dis }}$ and $F_{\mathrm{pol}}$ are the magnitudes of the solid-liquid interfacial dispersion interactions and polar interactions respectively. For most liquids, $F_{\text {dis }}$ was found to be close to 13 dynes $/ \mathrm{cm}^{2}$ (Yeh et al., 1991b). $F_{\text {pol }}$ was calculated by

$$
F_{p o t}=19.8 \exp \left(0.31 \frac{\varepsilon}{\sqrt{\sigma_{L}}}\right)
$$

where $\varepsilon$ is a dielectric constant.

\subsection{Shapiro and Stenby Equations}

Due to its limitations, the vapor pressure in porous media for non-ideal systems cannot be predicted by the Kelvin equation which assumes the ideal behavior of the liquid and the vapor. Shapiro and Stenby introduced two new equations estimating the pressure exerted at the curved liquid-vapor interface: one for a non-ideal single component and the other for multicomponent mixtures. These equations were developed for hydrocarbon mixtures in oil-gas-condensate reservoirs.

For a non-ideal single component, the condition of equilibrium for the two phases can be written in terms of the chemical potential, $\mu$, at a given pressure, $P$ :

$$
\begin{aligned}
\mu_{v}\left(P_{v}\right) & =\mu_{L}\left(P_{L}\right) \\
\text { and } \quad \mu_{v}\left(P_{d}\right) & =\mu_{L}\left(P_{d}\right)
\end{aligned}
$$


where subscript $\mathbf{v}$ denotes vapor phase, and $L$ denotes liquid phase. $P_{d}$ is defined as the dew pressure without porous media. After taking the difference of these two equations, the chemical potential of the vapor and the liquid can be written as

$$
\mu_{v}\left(\mathbf{P}_{v}\right)-\mu_{v}\left(\mathbf{P}_{d}\right)=\mu_{L}\left(P_{L}\right)-\mu_{L}\left(\mathbf{P}_{d}\right)
$$

Under the action of capillary forces, the pressure exerted at the curved liquid-vapor interface, $P_{\text {curv, }}$ is defined as

$$
P_{\text {curv }}=P_{L}-P_{v}
$$

Since the chemical potential of a pure compound can be written as $\int V,(P) d P$ at constant temperature, after substituting $P_{\text {curv }}$ and assuming incompressibility of the liquid, equation 2.3.3 becomes

$$
\int_{P_{d}}^{P_{1}} V(P) d P=V_{L}\left(P_{L}-P_{d}\right)=V_{L} P_{\text {arv }}+V_{L}\left(P_{v}-P_{d}\right)
$$

Equation 2.3.5 was simplified further using

$$
\frac{P V_{v}}{z}=R T
$$

where $\mathrm{z}$ is the compressibility factor. The vapor pressure $P_{v}$ was then changed to the relative pressure $\chi=P_{v} / P_{d}$, and the compressibility factor $z\left(P_{v}\right)$ was changed to $Z(\chi)=$ $z\left(P_{v}\right) / z\left(P_{d}\right)$. Equation 2.3.5 was then transformed to

$$
\int_{d}^{\chi} \frac{Z(\chi)}{\chi} d \chi=\frac{V_{L} P_{\text {curv }}}{V_{v}\left(P_{d}\right) P_{d}}+\frac{V_{L}}{V_{v}\left(P_{d}\right)}(\chi-1)
$$

The values of $Z(x)$ were assumed to be

$$
\int_{1}^{x} \frac{Z(x)}{x} d x \approx Z_{a v}(x) \ln x
$$


where $Z_{\mathrm{av}}$ is some characteristic average ratio of vapor compressibilities for the pressures between $P_{v}$ and $P_{d}$. After substitution, the pressure at curved liquid-vapor interface, $P_{\text {curv, }}$ was found as

$$
P_{\text {curv }}=P_{d}\left[\left(\frac{V_{v}\left(P_{d}\right)}{V_{L}}\right) Z_{a v} \ln \chi-\chi+1\right]
$$

where $\chi$ is a relative pressure defined as $P_{v} / P_{d}$. Compared to the original Kelvin equation, equation 2.3 .9 includes the vapor compressibility $Z_{\mathrm{av}}$ and the term $\chi-1$, which cannot be omitted when the molar volume of vapor is comparable with that of liquid. Another distinction of equation 2.3.9 is that, unlike Kelvin or Yeh et al. equations, the pressure in porous media is independent of the liquid surface tension and the contact angle between the liquid and the solid, parameters which are difficult to evaluate.

For the multicomponent system, the chemical potential of components in both phases were written as

$$
\mu_{v}^{i}\left(P_{v}, x_{v}\right)-\mu_{v}^{i}\left(P_{d}, x_{v}\right)=\mu_{L}^{i}\left(P_{L}, x_{L}\right)-\mu_{L}^{i}\left(P_{d}, x_{L d}\right)
$$

Transforming the above equation yields

$$
\int_{P_{d}}^{P_{v}} V_{v, M L X}\left(P, x_{v}\right) d P=\int_{P_{d}}^{P_{L}} V_{L}\left(P, x_{L d}\right) d P+\int_{\alpha_{L}}^{x_{L}} \sum_{i=1}^{n} x_{L d}^{i} \frac{\partial \mu_{L}^{i}\left(P_{1}, x\right)}{\partial x} d x
$$

At the dew point, $x_{L}$ is assumed to be close to $x_{L d}$, and the last term in equation 2.3.11 disappears. By assuming the incompressibility of liquid, the above equation becomes

$$
\int_{P_{d}}^{P_{v}} V_{v, M L X}\left(P, x_{v}\right) d P=V_{L} P_{c u r v}+V_{L}\left(P_{v}-P_{d}\right)
$$

where $\mathrm{V}_{\mathrm{V}, \mathrm{MIX}}$ is defined as

$$
V_{v, M I X}=\sum x_{L d}^{i} V_{v}^{i}
$$


By applying the relative pressure $\chi$ and average compressibility $Z, P_{\text {cur }}$ can be expressed

as

$$
\frac{P_{c u r v}}{P_{d}}=\left(\frac{V_{v, M L X}}{V_{L}} Z_{a v}-1\right)(x-1)+\frac{V_{v, M L X}}{V_{L}} Z_{a v}(x-1)^{2}
$$

$\mathrm{x}_{\mathrm{Ld}}{ }^{i}$ is defined as the liquid composition at dew pressure without porous media. However, when $V_{V_{v} \text { MIX }}$ and $V_{L}$ become equal, $P_{\text {curr }} / P_{d}$ turns out to be the order of $(\chi-1)^{2}$, thus the last term of equation 2.3.11 should not be omitted. The distinction of equation 2.3.14 from equation 2.3.9 is that the vapor volume is expressed in terms of the mixed volume $\mathrm{V}_{\mathrm{V} \mathrm{MIX}}$.

The advantage of using equations 2.3.9 and 2.3.14 is that the pore diameters and the liquid surface tension can be directly evaluated using

$$
P_{\text {curv }}=-\frac{2 \sigma \cos \theta}{r_{\text {curv }}}
$$

where $\theta$ is a contact angle between the liquid and the solid, and $\sigma$ is the liquid surface tension.

\subsection{Development of the SS mod Model and Computational Procedures}

As introduced by Yeh et al. (1991b), the vapor pressure in porous media can be calculated by evaluating the differences in the surface tension. However, the determination of the surface tension of a liquid in such small pores remains a challenge. Furthermore, the non-ideality of solution was omitted in both Kelvin and Yeh et al. equations. The equations developed by Shapiro and Stenby is more sound when the 
mixture behaves non-ideally. However, the simplification of their equations using compressibility factor is not necessary. For both single and multiple component solutions, the change in the chemical potentials in vapor phase can be written in a similar form (equations 2.3.5 and 2.3.12). Since the molar volume of non-ideal liquid solution can be easily calculated by the Peng-Robinson-Stryjek-Vera (PRSV) cubic equation of state (Stryjek and Vera, 1986) combined with the Sandoval-Wilczek-Vera-Vera (SWVV) mixing rule (Sandoval et al., 1989), the chemical potential in the vapor phase can easily be estimated by

$$
\int_{P_{d}}^{P_{V}} V(P) d P=\int_{P_{d}}^{P_{V}} d(P V)-\int_{P_{d}}^{P_{V}} P d V=(P V)_{P_{V}}-(P V)_{p_{d}}-\int_{d_{d}}^{V_{V}} P d V
$$

Subsequently, $\mathbf{P}_{\mathrm{cur}}$ for both single and multiple component solution can be expressed in terms of

$$
P_{\text {curv }}=\frac{1}{V_{L}}\left[(P V)_{P_{v}}-(P V)_{P_{d}}-\int_{d} P d V-V_{L}\left(P_{v}-P_{d}\right)\right]
$$

where $\int P d V$ can be calculated by analytical integration of PRSV equation of state. Equation 2.4.2 is called the $\mathrm{SS}_{\text {mod }}$ model, the modified version of Shapiro and Stenby, and used to predict the VLE in porous media studied in this work.

Equation 2.4.2 was solved by first calculating the surface tension of liquids using the Winterfeld correlation given in Perry's Chemical Engineering Handbook (1997). The $\mathrm{SS}_{\text {mod }}$ model predictions were calculated by using the PRSV equation of state coupled with the SWVV mixing rule. These computational procedures are summarized in Appendices A and B. Note that the effects of the pore shapes and the contact angle, $\theta$, are 
not yet taken into account in the model. The pores were assumed cylindrical, and the contact angle was assumed to be independent of the pore sizes.

The $\mathrm{SS}_{\mathrm{mod}}$ model was solved to predict the VLE of two aqueous alcohol solutions, ethanol-water and propanol-water, and two binary alcohol solutions, methanolisopropanol and ethanol-n-octane in porous media as a function of pore diameters. The model predictions were compared with the results of experiments conducted by using sintered metal and fritted glass plates as porous media. The following chapter summarizes the experimental apparatus and procedures used in this work. 


\subsection{EXPERIMENTAL APPARATUS AND PROCEDURES}

The experiments determining the vapor and liquid equilibrium (VLE) were conducted using glass vials containing porous media, a Genesis headspace autosampler and a Varian 3400 gas chromatograph (GC). This apparatus was first used in Wong's experiments (1997). Its schematic diagram is shown in Figure 3.1. As porous media, sintered metal plates with a nominal pore size of $40 \mu \mathrm{m}$ and fritted glass plates with a nominal pore size of $4-8 \mu \mathrm{m}$ were used. Prior to the vapor-liquid equilibrium experiments, the following key experimental variables were determined: time required to reach equilibrium in the vial, the factor to convert the GC output to the vapor mole fractions and the liquid volume capacity of the porous media. This chapter summarizes the experimental apparatus in Section 3.1 and the procedures determining the experimental variables in Section 3.2.

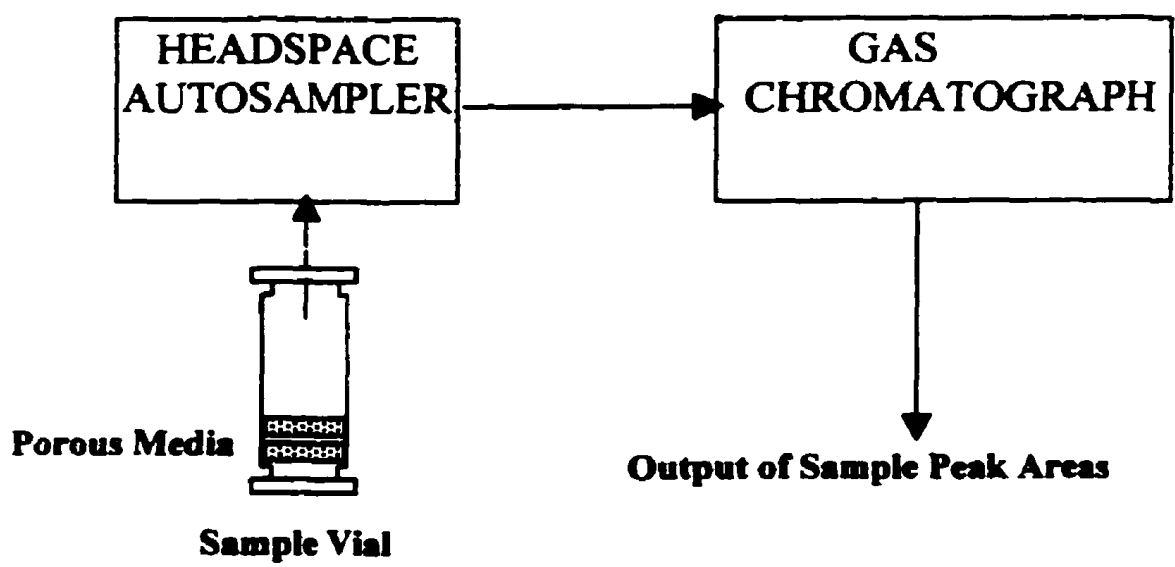

Figure 3.1: Schematic (not drawn to scale) of VLE Analysis 


\subsection{Experimental Apparatus}

The experimental apparatus used in this study can be divided into the vials with and without porous media, headspace autosampler and gas chromatograph. As shown in Figure 3.1, a liquid of known concentration was loaded into the glass vials. When the vapor and liquid equilibrium was reached in the vials, the vapor sample was taken by the autosampler and sent to the GC for analysis. In this section, the principles of each element and its parameters are explained.

\subsubsection{Vials and Porous Media}

The glass vials were specially made from two Pyrex glass vials fused together to create openings at the top and the bottom. The vials were originally designed by Wong (1997) to accommodate top and bottom septa through which vapor samples were taken and the liquid level was adjusted. The dimensions for each vial were $70 \mathrm{~mm}$ in length and $21.5 \mathrm{~mm}$ in inner diameter (Figure 3.2) to fit into the autosampler.

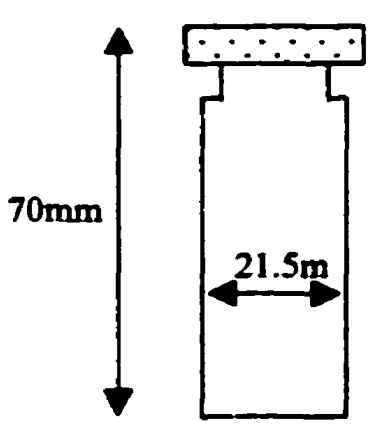

(a)

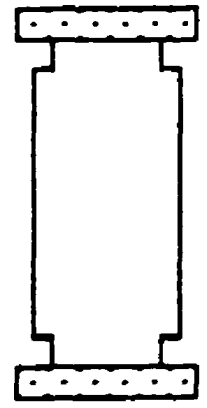

(b)
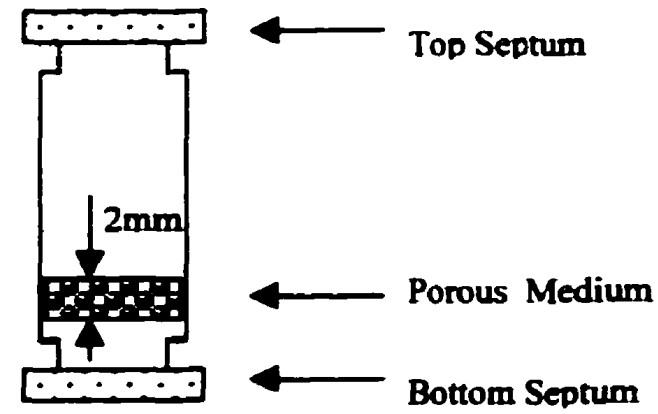

(c)

Figure 3.2: Schematic (not drawn to scale) of Glass Vials:

(a) Pyrex Glass Vial, Unmodified, (b) Modified, (c) With Porous Medium 
Butyl rubber stoppers were used as septa and were secured by aluminum caps. Sintered metal and fritted glass plates were used as porous media, and their specifications are tabulated in Table 3.1 .

Table 3.1: Summary of Porous Plate Specifications

\begin{tabular}{|l|l|l|}
\hline Plate Type & Nominal Pore Diameter & Supplier \\
\hline Sintered Metal & $40 \mu \mathrm{m}$ & Pall Canada \\
\hline Fritted Glass & Type E $(4-8 \mu \mathrm{m})$ & Ace Glass \\
\hline
\end{tabular}

\subsubsection{Headspace Autosampler}

A Genesis headspace autosampler consisting of a carrousel, a heated platen, a control panel and a septum needle adapter connected to a sample loop, was used for the sampling (Figure 3.3). The biggest advantage of using the autosampler is the precision of the sample volume withdrawn from the vial. The carrousel can hold upto fifty $22 \mathrm{~mL}$ vials, and a maximum of twelve vials can be simultaneously heated in the platen.

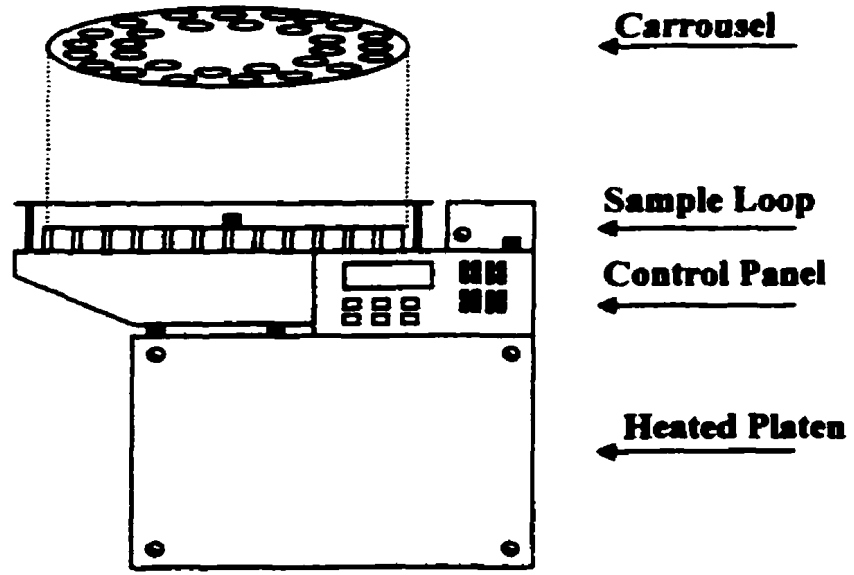

Figure 3.3: Schematic (not drawn to scale) of Headspace Autosampler 
Once the vapor-liquid equilibrium was reached, each vial was raised onto the needle, and the vapor sample was withdrawn. Static pressure established in the vial upon heating forced the samples into the sample loop (loop fill mode). The static vial pressure of 2 to 3 psig was recommended for reproducibility of data and safety (Varian, 1991). The sample in the loop was then sent to the GC for analysis by Helium carrier gas (inject mode). More detailed diagrams of loop fill and inject modes are shown in Figures 3.4 and 3.5.

In the loop fill mode, the vent valve is open, and the vapor sample flows into the loop due to the static vial pressure (Figure 3.4). The loop fill time needs to be long enough to permit complete exhausting of the loop contents, and yet short enough to prevent any disruption of the vapor-liquid equilibrium established in the vial. The sample is then retained in the loop for a short time to equilibrate to the loop temperature and pressure (loop equilibrium time) before being swept to the GC by Helium carrier gas.

Figure 3.5 illustrates the inject mode. The sample loop is placed in line with the column carrier gas, and the loop content is transferred into the GC. The volume of carrier gas required to inject the sample is at least 2 to 5 times the volume of the loop. Thus, knowing the gas flow rate, the injection time required to flush the sample loop was calculated. Note that pressurization gas was not used in the experiment to prevent disruption of the equilibrium established in the vial. 


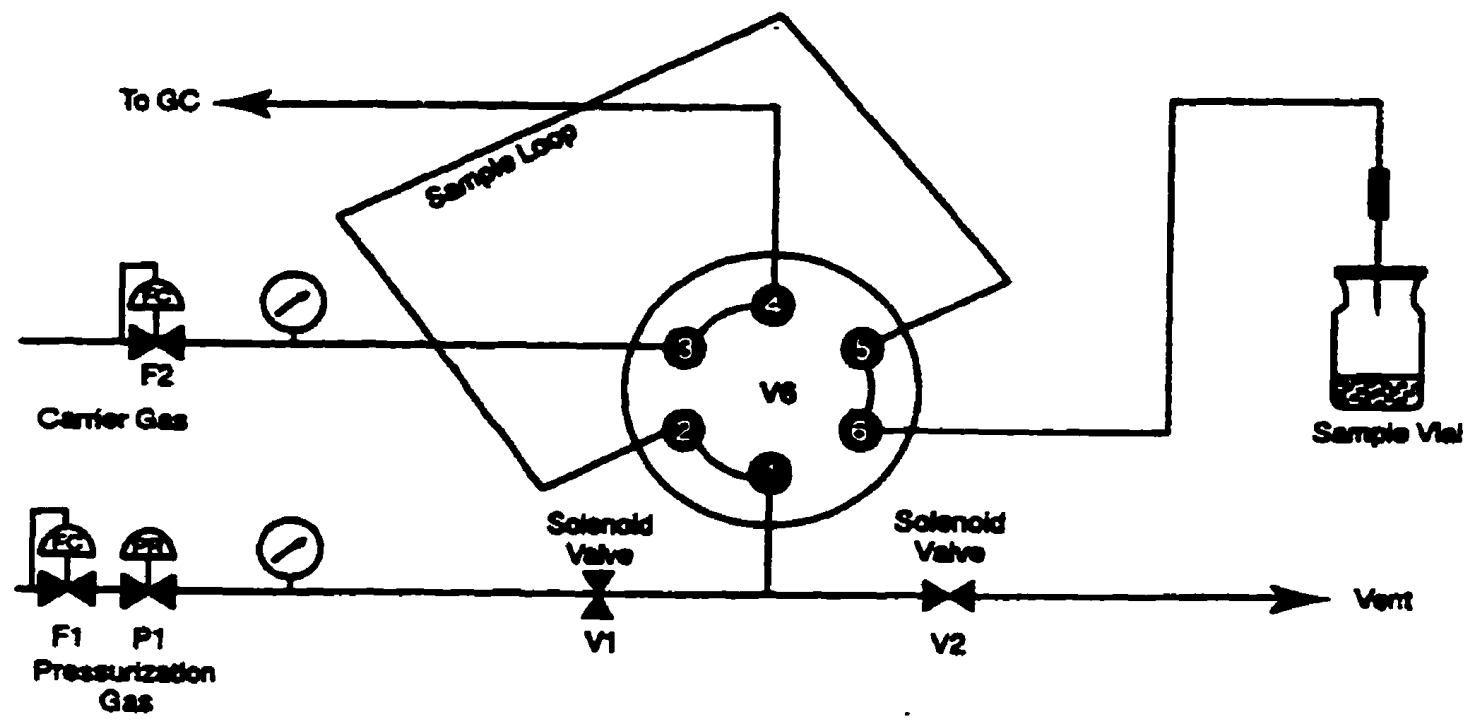

Figure 3.4: Schematic of Loop Fill Mode (Varian, 1991)

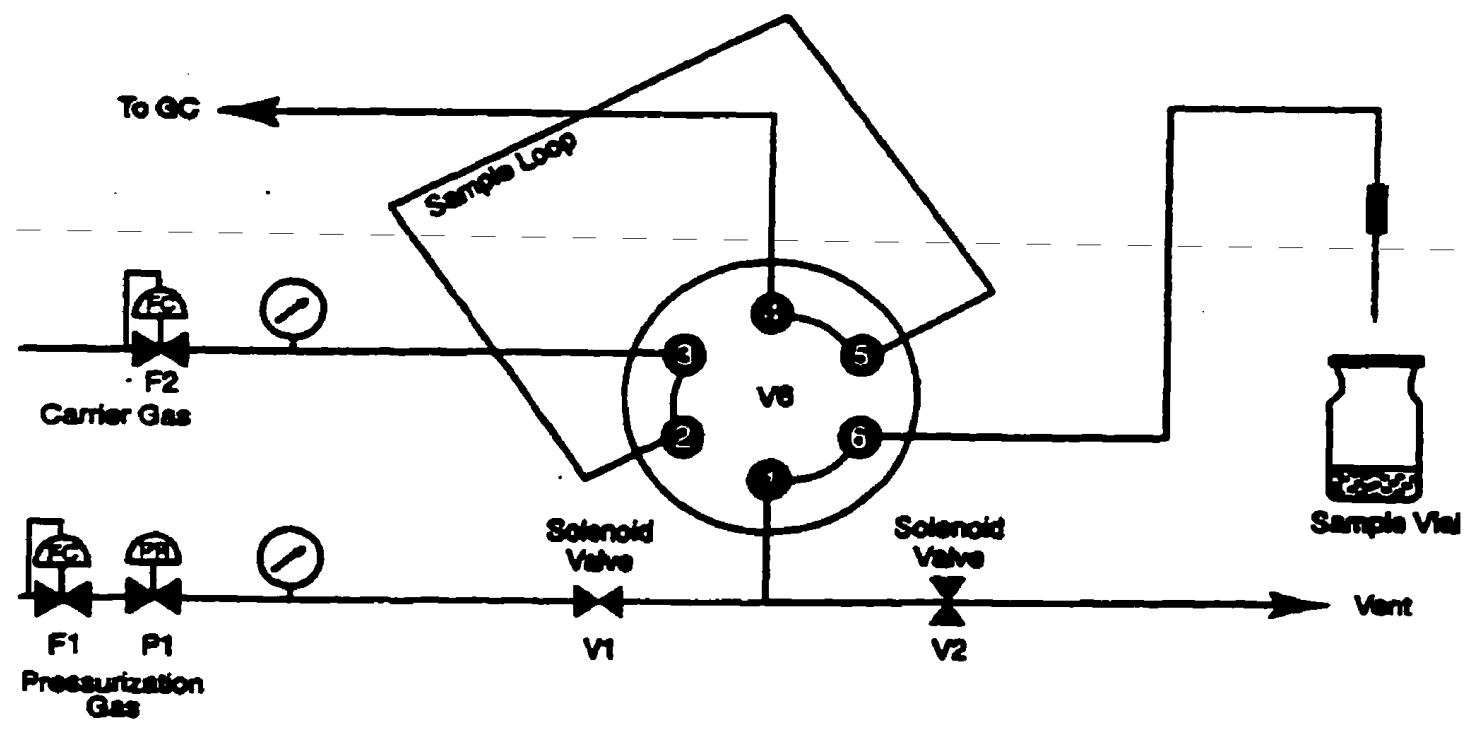

Figure 3.5: Schematic of Inject Mode (Varian, 1991) 
A summary of the autosampler parameters is shown in Table 3.2. The platen temperature was set to achieve the static pressure of 2 to $3 \mathrm{psig}$. For ethanol-water solutions, the platen temperature was set at $60^{\circ} \mathrm{C}$ in order to reproduce Wong's experiments (1997). The equilibrium time was determined experimentally according to the procedures described in Section 3.2.1. The line and valve temperatures were set at $175^{\circ} \mathrm{C}$ to prevent any possible condensation of samples.

Table 3.2: Summary of Autosampler Parameters

\begin{tabular}{|l|l|}
\hline Model & $\begin{array}{l}\text { Genesis Headspace Autosampler with 50- } \\
\text { position carrousel }\end{array}$ \\
\hline Injector Inlet Connection & Septum needle adapter \\
\hline Carrier Gas & Ultra High Purity Helium (Matheson) \\
\hline Carrier Gas Flow Rate & $15 \mathrm{cc} / \mathrm{mim}$ \\
\hline Platen Temperature & $55{ }^{\circ} \mathrm{C}$ (for methanol-isopropanol) \\
& $75{ }^{\circ} \mathrm{C}$ (for ethanol-n-octane) \\
\hline Equilibrium Time & $60{ }^{\circ} \mathrm{C}$ (for ethanol-water) \\
\hline Line \& Valve Temperature & $990 \mathrm{~min}$ \\
\hline Loop Fill Time & $175^{\circ} \mathrm{C}$ \\
\hline Loop Equilibrium Time & $0.03 \mathrm{~min}$ \\
\hline Injection Time & $0.30 \mathrm{~min}$ \\
\hline Sample Loop Volume & $2.00 \mathrm{~min}$ \\
\hline
\end{tabular}

\subsubsection{Gas Chromatograph (GC)}

The vapor sample sent from the autosampler was analyzed by a Varian 3400 GC and the Analog-to-Digital Converter (ADC) board controlled by a computer using the software Star Workstation. The schematic of the GC is shown in Figure 3.6. The vapor 
sample injected from the autosampler passes through the GC capillary column whose inner surface is coated with stationary liquid phase (McNair and Miller, 1997). Depending on their affinities, the vapor contents pass through the column at different velocities (retention time) resulting in the separation of each analyte, which is then flame ionized and detected by the Flame Ionization Detector (FID). The signals from the FID are then converted to digital signals by $A D C$ board to give the relative peak areas.

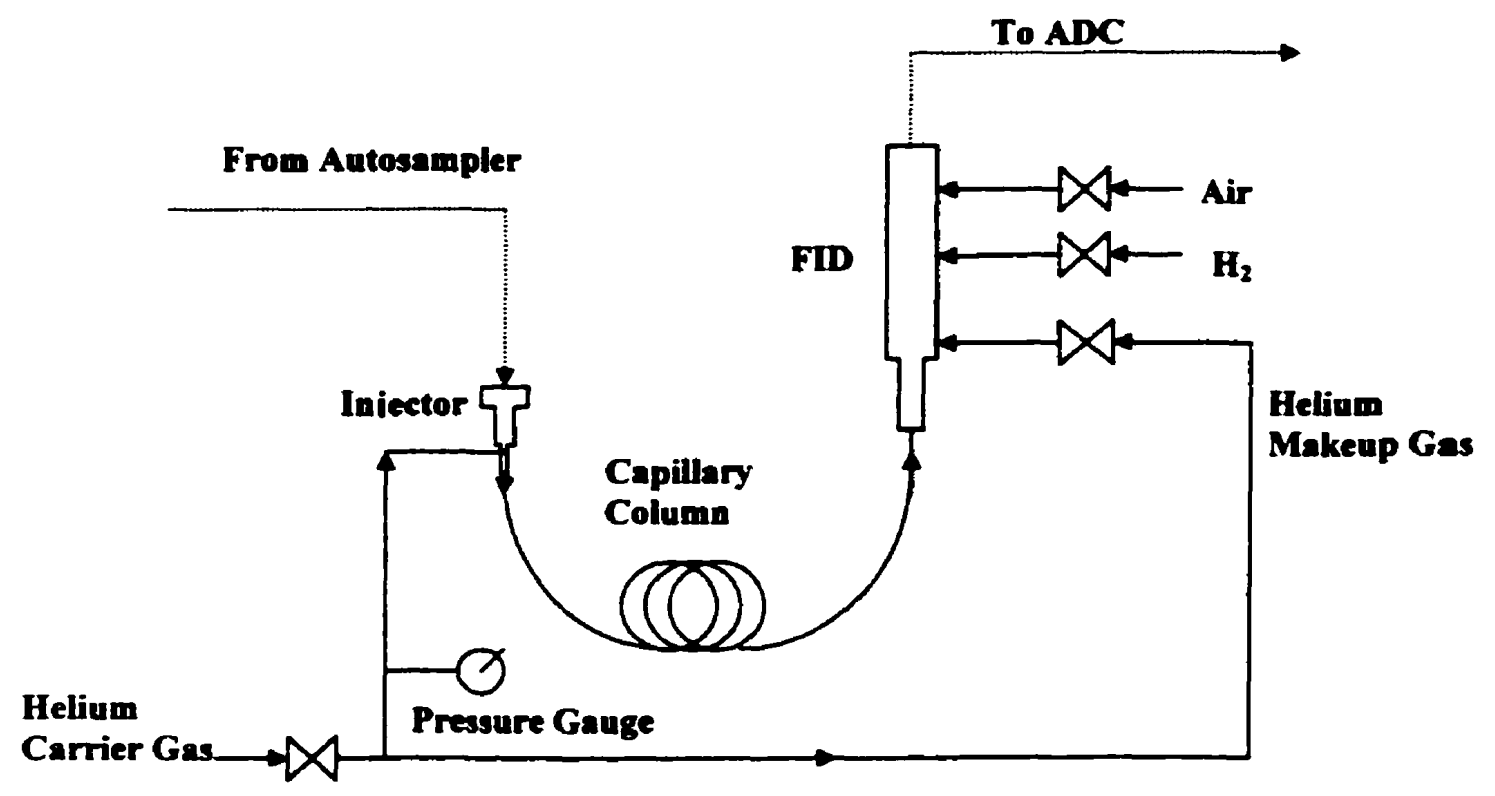

Figure 3.6: Schematic (not drawn to scale) of GC (McNair and Miller, 1997)

McNair and Miller (1997) explain the principles of the Flame Ionization Detectors (FIDs). The analytes are burned in a small oxy-hydrogen flame producing ions, which are detected as a current signal. The signal is approximately proportional to the carbon content, giving rise to the so-calied equal per carbon rule. All hydrocarbons should show the same response. For example, methane has relative response of 1 , ethane, 2, propane, 
3 and so on. However, the response factors (moles of sample/peak area) vary due to the presence of oxygen or nitrogen and are dependent on the column parameters, gas flow rates and the FID sensitivity. Thus, the response factor for a given compound and for a given GC column must be determined experimentally. The experimental procedures to determine the response factors for the compounds studied in this work are explained in Section 3.2.2.

A summary of GC parameters is shown in Table 3.3. The column temperatures were set at $65^{\circ} \mathrm{C}$ for ethanol-water and $95^{\circ} \mathrm{C}$ for methanol-isopropanol and ethanol-noctane. Note that the column was ramped to $150^{\circ} \mathrm{C}$ for 2 minutes to remove any carryover after each sample. For complete removal of the carryover, one vial containing distilled water was used as a blank between samples.

Table 3.3: Summary of Gas Chromatograph Parameters

\begin{tabular}{|l|l|}
\hline Model & Varian 3400 Gas Chromatograph \\
\hline Column & DB-624 glass capillary column \\
\hline Column Temperature & $65^{\circ} \mathrm{C}$ (for ethanol-water) \\
& $95^{\circ} \mathrm{C}$ (for binary alcohol mixtures) \\
\hline Ramping Temperature & $150^{\circ} \mathrm{C}$ \\
\hline Ramping Time & $2 \mathrm{~min}$ \\
\hline Detector & Flame Ionization Detector (FID) \\
\hline Detector Sensitivity & 12 \\
\hline Detector Temperature & $250^{\circ} \mathrm{C}$ \\
\hline Injector Temperature & $180^{\circ} \mathrm{C}$ \\
\hline Make - Up Gas & $\mathrm{Ultra} \mathrm{High} \mathrm{Purity} \mathrm{Helium}$ \\
\hline Make - Up Gas Flow Rate & $15 \mathrm{cc} / \mathrm{min}$ \\
\hline Air Flow Rate & $300 \mathrm{cc} / \mathrm{min}$ \\
\hline Hydrogen Gas Flow Rate & $30 \mathrm{cc} / \mathrm{min}$ \\
\hline
\end{tabular}




\subsection{Experimental Procedures}

The sampling and analysis were carried out using the vials and porous media, autosampler and gas chromatograph described in the previous section. This section summarizes the experimental methods for determining the equilibrium time, the response factors and the liquid volume used in each vial. All tests were repeated at least three times and the standard deviations are indicated in all figures. Note that the error bars are so narrow that, in most figures, they are very difficult to see.

\subsubsection{Determination of Equilibrium Time}

The vials containing $60 \mathrm{~mol} \%$ of methanol in isopropanol were heated in the platen for two to twelve hours, and the mole fraction of methanol in the vapor was plotted as a function of heating time (Figure 3.7). The mole fraction of methanol had a standard deviation greater than $2 \%$ when heated for less than 750 minutes. Similar experiments were performed with ethanol-n-octane and ethanol-water mixtures, and the minimum equilibrium times of 900 and 350 minutes were obtained respectively. Thus, in order to ensure equilibrium, 990 minutes of equilibrium time were used in all experiments. With the porous media, the vials were prepared and preheated in an oven at the required temperature for 24 hours before being placed on the carrousel. This extra time ensured diffusion of vapor samples through the pores. 


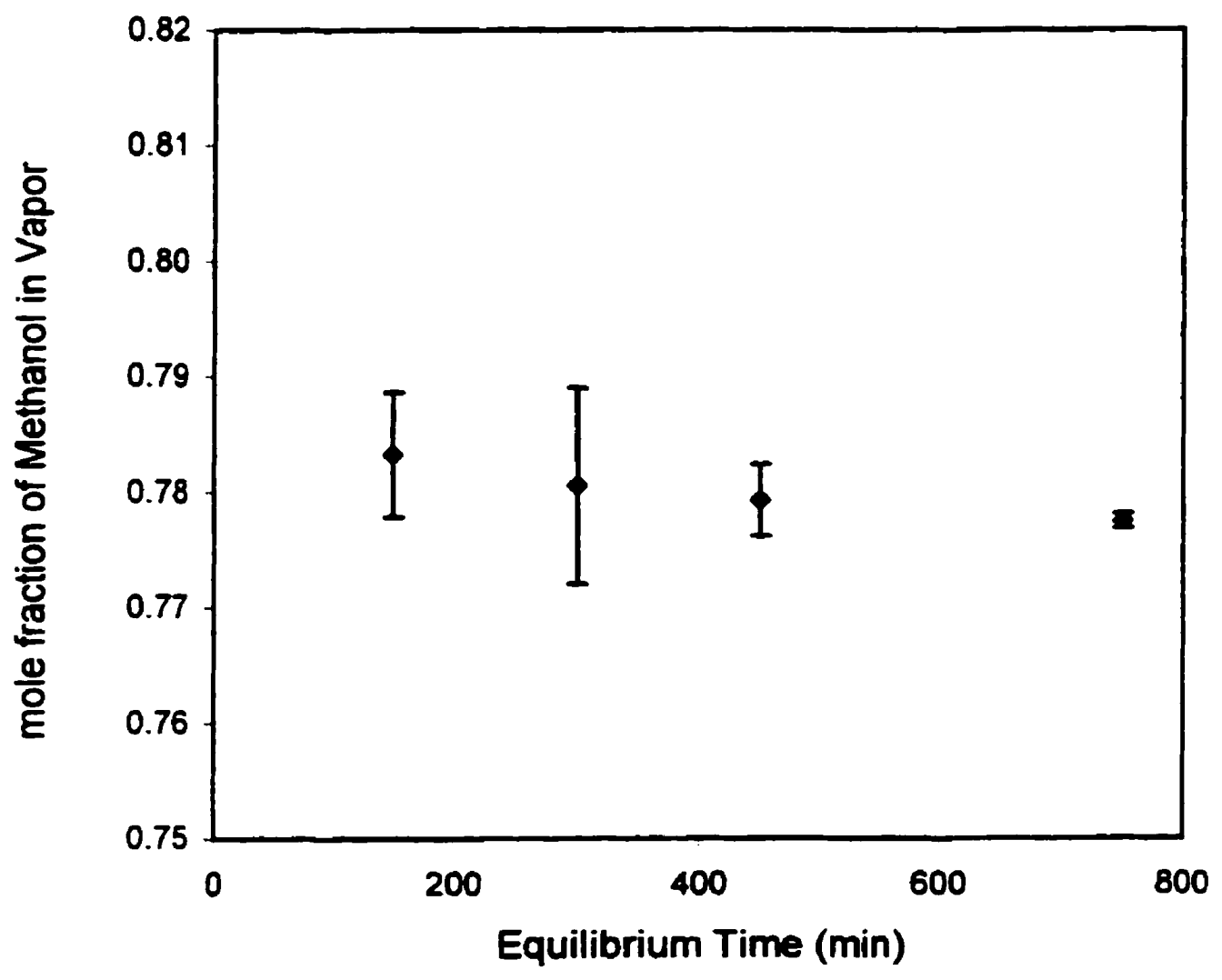

Figure 3.7: Minimum Equilibrium Time for $60 \mathrm{~mol} \% \mathrm{MeOH}$ Solution with $95 \%$ Confidence Intervals 


\subsubsection{Response Factors (K Factors) for Non-Aqueous Systems}

As mentioned in Section 3.1.3, in order to convert the peak area to the actual number of moles of the analyte in the sample, the response factor for a given compound must be determined experimentally by manual liquid injection. The response factor, also called $\mathrm{K}$ factor, is defined as (Béland, 1998)

$$
K_{A}=\frac{\# \text { of moles of } A \text { in liquid sample }}{\text { peak area of } A}=\frac{\text { weight of } A \text { in the sample } \times \frac{1}{M W}}{\text { peak area of } A}
$$

where A denotes analyte $\mathrm{A}$, and MW denotes its molecular weight. According to Béland (1998), the liquid sample volume injected to the GC should be exactly $1 \mu \mathrm{L}$, and the weight of the analyte in the sample should be less than 10ng. Thus, in order to find an appropriate dilution, $95 \mu \mathrm{L}$ of methanol were diluted in various volumes of distilled water (10 to $50 \mathrm{~mL}$ ). One micro liter of each diluted solution was directly injected into the GC using a syringe. Knowing the dilution factor, the actual number of moles of methanol injected to the GC was calculated, and thus, the $K$ constant was determined. The measurements were repeated six times and are plotted in Figure 3.8. The peak areas for liquid samples containing $0.08-0.09 \mathrm{nmol}$ of analyte (linear region in the figure) were in the same order of magnitude as the peak areas for $5 \mu \mathrm{L}$ gas samples injected from the autosampler. The standard deviation less than $2 \%$ was also obtained in this region. Thus, the appropriate dilution was determined to be with $95 \mu \mathrm{L}$ of solute in $10 \mathrm{~mL}$ of solvent and used for other alcohol compounds. For n-octane, ethanol was used as a solvent. 


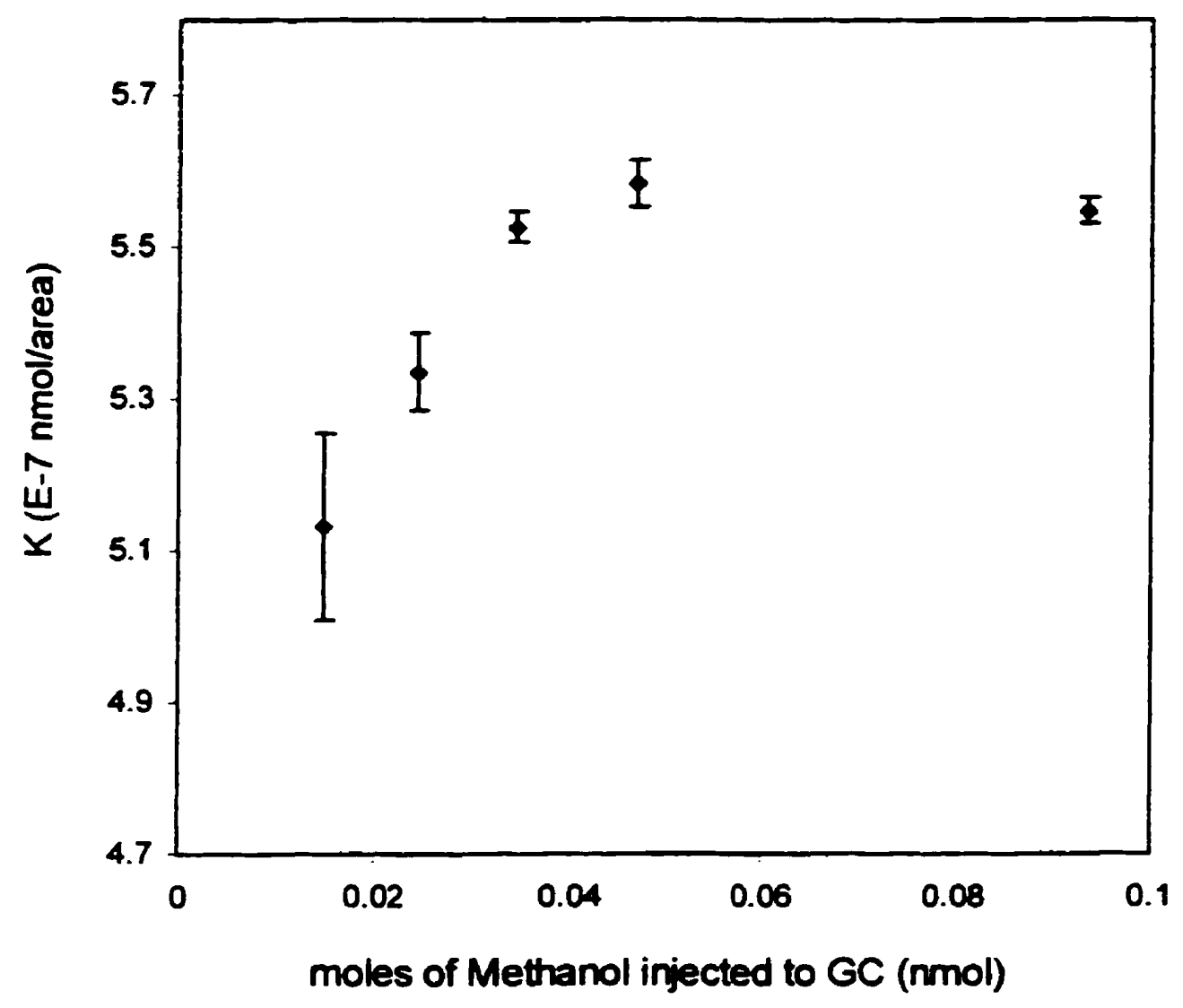

Figure 3.8: Determination of Response Factor for Methanol with $95 \%$ Confidence Intervals 
Since FID detectors are known to drift as a function of time, the $\mathrm{K}$ factors were confirmed on a regular basis both with manual injections and with internal standards. Using $\mathrm{K}$ factors, the VLE of methanol-isopropanol and ethanol-n-octane mixtures without porous media were obtained. Figures 3.9 and 3.10 show the experimental results compared with literature values. The $95 \%$ confidence intervals, produced from triplicate samples, were too small to show up in these figures. This result indicates that the experimental apparatus and procedures used in this study allow precise and reproducible vapor phase analyses.

\subsubsection{Response Factors for Aqueous Systems}

For ethanol-water mixtures, however, the mole fraction of ethanol in the sample could not be directly calculated since water was not detected by the GC. Thus, the calibration curve converting the peak area to the ethanol mole fraction in the vapor was generated by using the VLE data available in literature (Gmehling, 1981). Figure 3.11 shows the calibration curve at $60^{\circ} \mathrm{C}$. Experimental data comparing the analyses methods are tabulated in Appendix $\mathbf{D}$. 


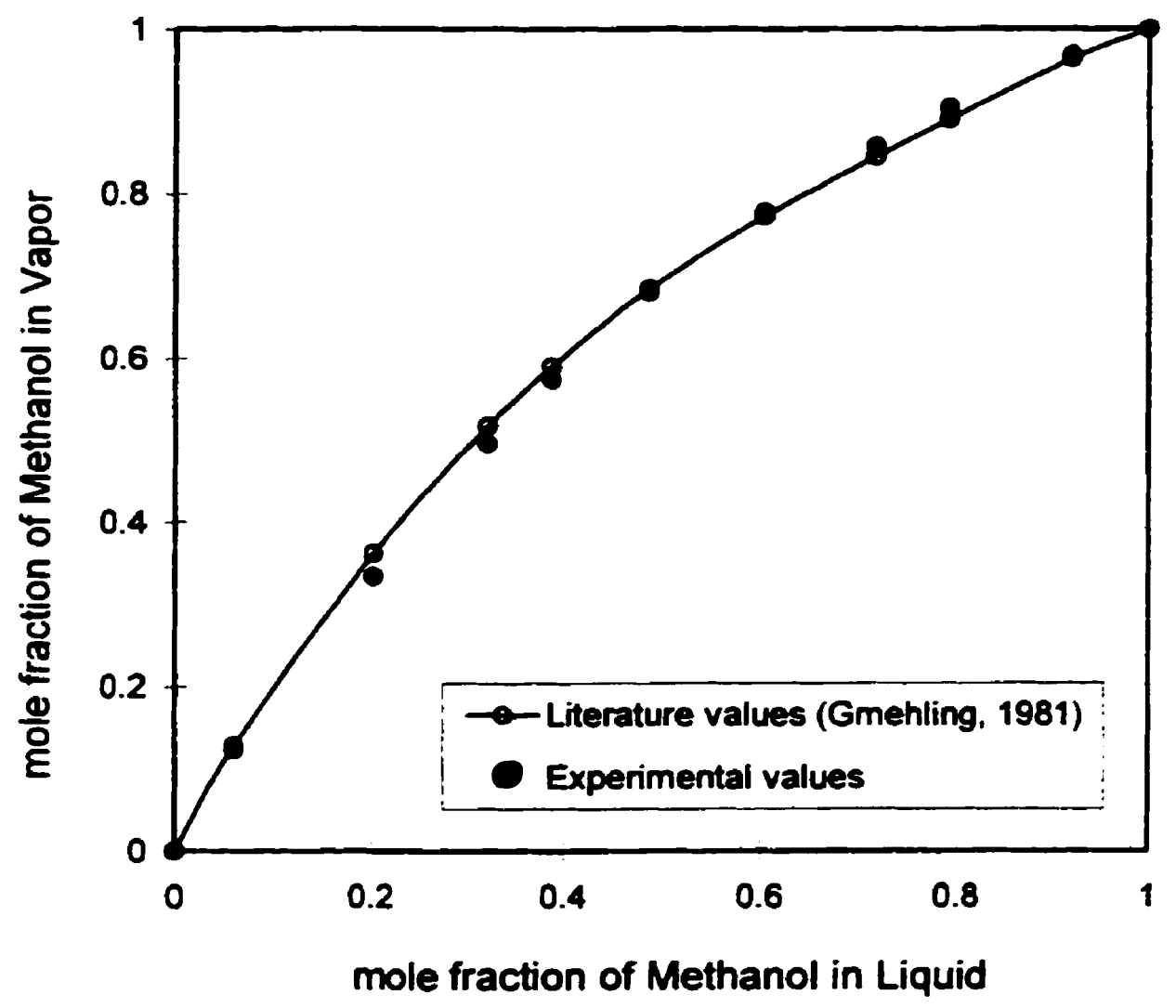

Figure 3.9: VLE of Methanol-Isopropanol w/o Porous Media $\left(55^{\circ} \mathrm{C}\right)$ with $95 \%$ Confidence Intervals 


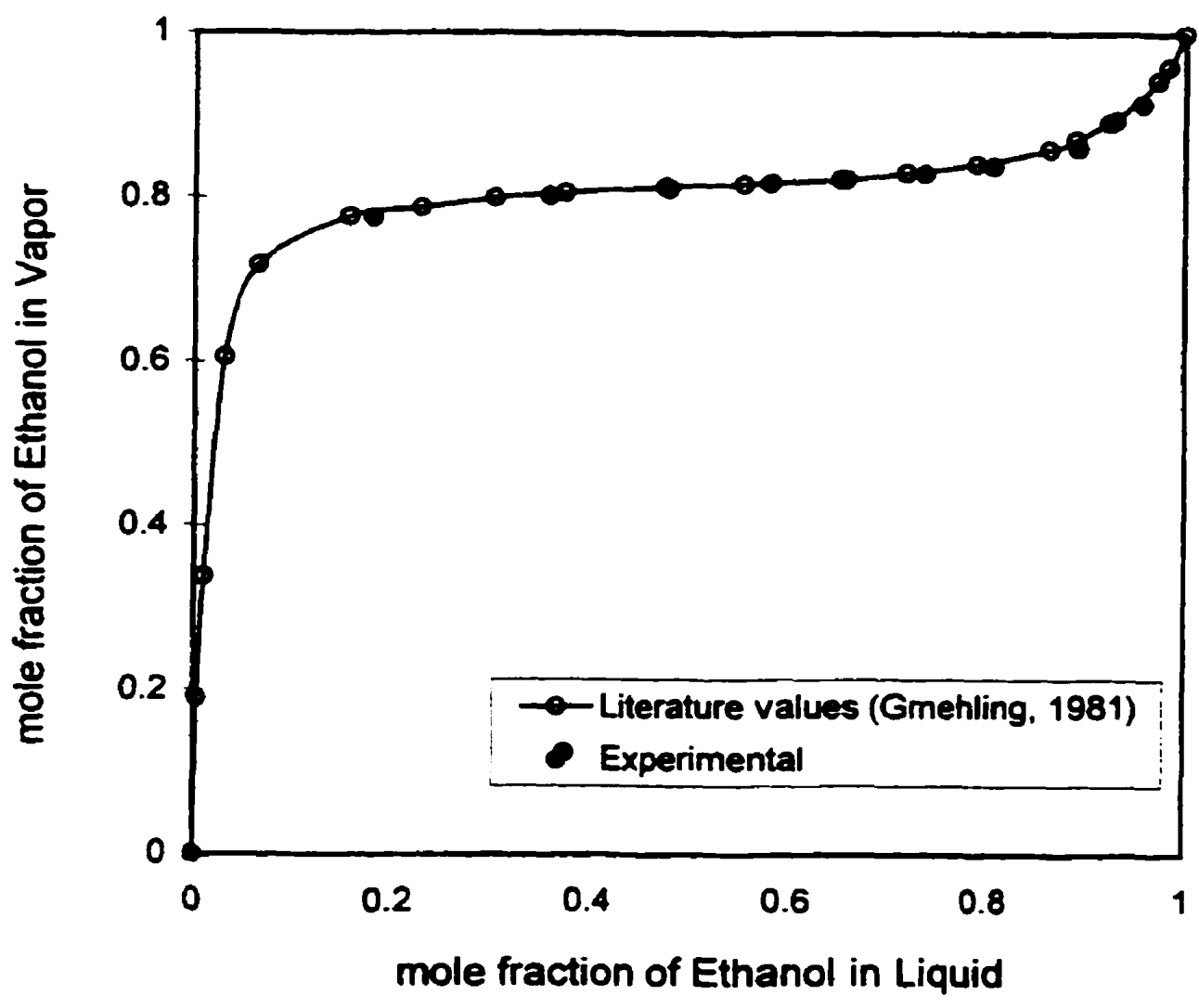

Figure 3.10: VLE of Ethanol-n-Octane w/o Porous Media $\left(75^{\circ} \mathrm{C}\right)$ with $95 \%$ Confidence Intervals 
29

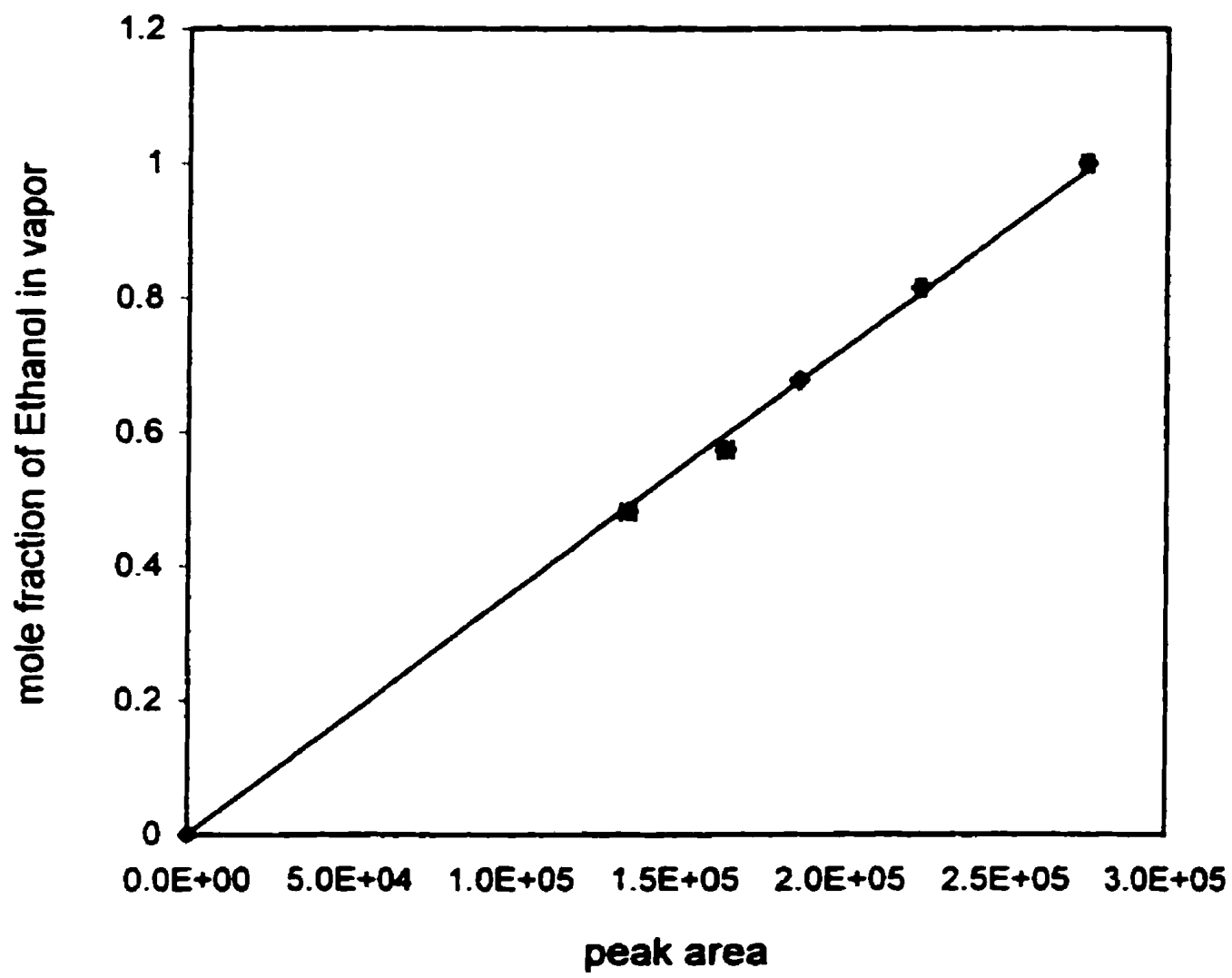

Figure 3.11: Calibration of Peak Area to Mole Fraction of Ethanol in Water with $95 \%$ Confidence Intervals 


\subsubsection{Determination of Liquid Volume in the Vlals}

The most critical criterion in the experiments measuring the vapor and liquid equilibria in porous media was to ensure that the liquid-vapor surface was formed within the plate. Originally, the experiments were designed so that each porous medium was held in the middle of a glass vial by epoxy. Bulk solution was loaded into the space below the plate, and the liquid level was adjusted to ensure the liquid-solid interface formed within the plate. However, it was later found that upon heating, the liquid expanded sufficiently to flood the plate. A thin liquid film formed on the plate surface thereby caused a canceling of the liquid surface modification effect. Furthermore, the capillary force in such small pores is sufficient enough to pull the liquid more than $1.5 \mathrm{~m}$ when the liquid is in excess underneath the plate. It was then decided to use only as much liquid as could be held in the porous medium. The solution was pipetted directly onto the plate until a thin film of liquid was observed on the surface of the plate. The maximum volume of liquid held by one porous plate was found to be $0.2 \mathrm{~mL}$.

The vapor and liquid analyses of vials containing $0.2 \mathrm{~mL}$ of liquid, however, showed that the liquid composition on the plate changed enough to alter the equilibrium upon heating. A bulk solution of $45 \mathrm{~mol} \%$ methanol-isopropanol mixture was loaded into the unmodified vials at various liquid volumes ranging from $0.02 \mathrm{~mL}$ to $10 \mathrm{~mL}$. The vials were brought to equilibrium and analyzed for vapor and liquid concentrations (Table 3.4). The liquid was analyzed by rinsing the vials with distilled water and injecting the solution manually into the GC. Vials containing liquid volumes of $10 \mathrm{~mL}$ were used as controls. When the liquid volume in the vial was $0.02 \mathrm{~mL}$, most of liquid was vaporized and 
showed the vapor concentration approximately equal to the bulk concentration. The liquid volume of $0.4 \mathrm{~mL}$ was found to be sufficient to yield the same vapor and liquid concentrations as the control. Since the maximum liquid volume held by each plate was found to be $0.2 \mathrm{~mL}$, the vials were prepared consisting of two porous media for the VLE experiments.

Table 3.4: Mole fraction of Methanol in Isopropanol as a Function of Liquid Volume

\begin{tabular}{|c|c|c|}
\hline Liquid Volume (mL) & Vapor Phase & Liguid Phase \\
\hline 0.02 & 0.4533 & - \\
\hline 0.025 & 0.4890 & 0.5189 \\
\hline 0.05 & 0.5597 & - \\
\hline 0.1 & 0.6100 & 0.4418 \\
\hline 0.2 & 0.6277 & 0.4384 \\
\hline 0.3 & 0.6475 & 0.4547 \\
\hline 0.4 & 0.6455 & 0.4459 \\
\hline 0.5 & 0.6496 & 0.4478 \\
\hline Control $(10 \mathrm{~mL})$ & 0.6476 & 0.4457 \\
\hline
\end{tabular}

Using this new set of vials, the VLE of ethanol-water in sintered metal plates with a nominal pore size of $40 \mu \mathrm{m}$ obtained by Wong (1997) was reproduced. The VLE of methanol-isopropanol and ethanol-n-octane in $40 \mu \mathrm{m}$ sintered metal and 4-8 $\mu \mathrm{m}$ fritted glass plates were measured. These experimental results were compared with the model predictions in the following chapter. 


\subsection{RESULTS AND DISCUSSION}

The $\mathrm{SS}_{\mathrm{mod}}$ model was used to predict the vapor and liquid equilibria (VLE) in 40 and $5 \mu \mathrm{m}$ pores for two aqueous alcohol mixtures, ethanol-water and propanol-water and two binary alcohol mixtures, methanol-isopropanol and ethanol-n-octane. These model predictions were compared with the experimental results conducted with sintered metal of $40 \mu \mathrm{m}$ nominal pore size and fritted glass of $4-8 \mu \mathrm{m}$ nominal pore size as porous media. However, when measured under microscope, the pores in the plates were orders of magnitude larger than the nominal pore sizes stated by the manufacturer (Wong, 1997). Thus, the actual pore diameter in chosen porous media was re-evaluated and used in model predictions. In this chapter, the model predictions of the VLE as a function of pore sizes are summarized in Sections 4.1 and 4.2. The determination of actual pore sizes of the porous media based on the Wong's SEM measurements is presented in Section 4.3. Finally, Section 4.4 summarizes the comparison of model prediction with the experimental results.

\subsection{VLE in Porous Media as Function of Pore Sizes}

As per the theory presented in Chapter 2, the VLE is affected by the pore sizes of porous media. The percent increase in the vapor mole fraction for ethanol-water and methanol-isopropanol mixtures was plotted as a function of pore sizes (Figure 4.1). Note that each curve is specific for a given mixture at one concentration and temperature. 

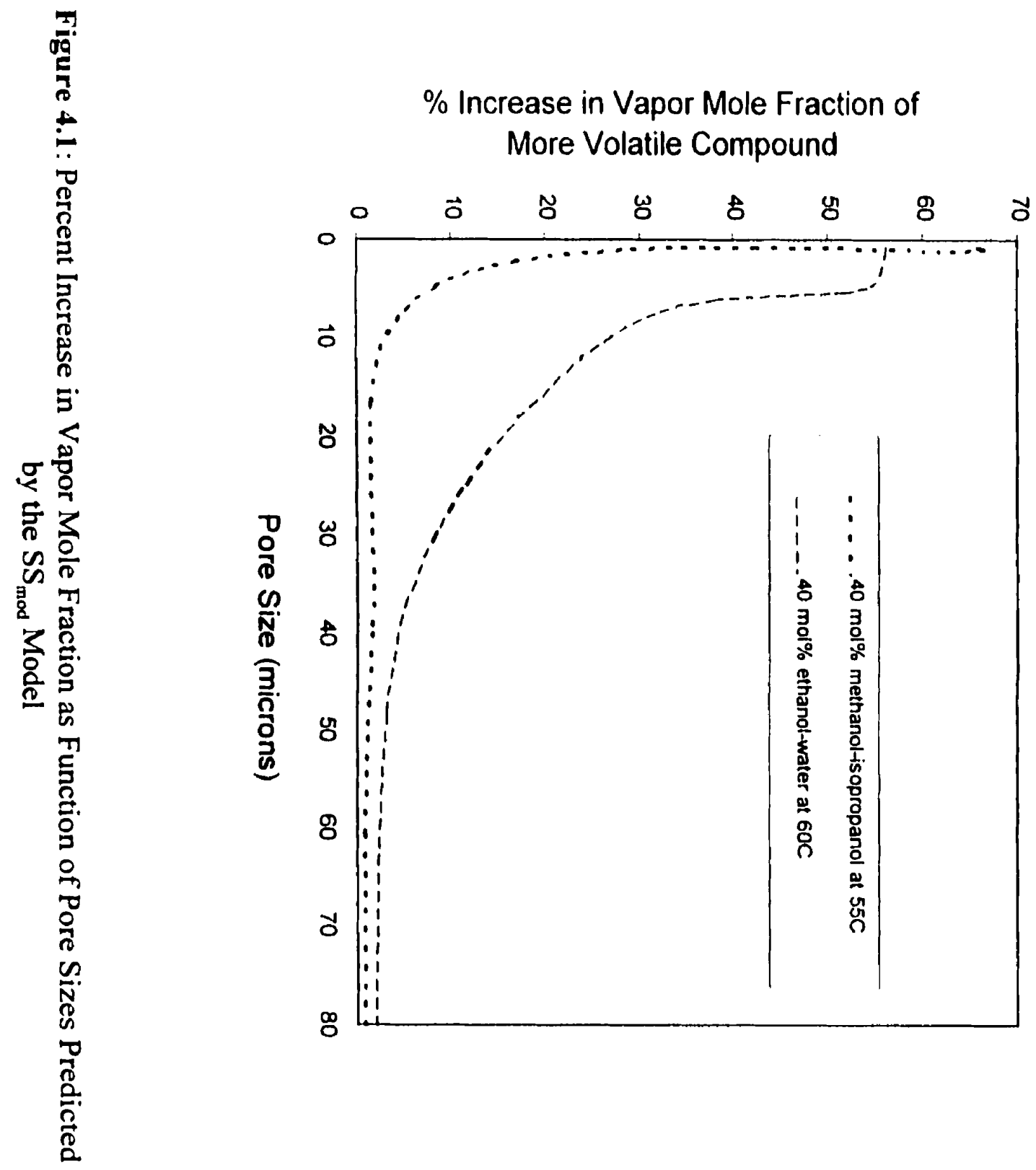
For both methanol-isopropanol and ethanol-water mixtures, the effect of curved liquid surface on the VLE decreases dramatically as the pore size increases. For pores greater than $80 \mu \mathrm{m}$, the difference in the vapor concentrations with and without porous media for both systems is predicted to be negligible. The curvature effect on the VLE increases rapidly as the pore size decreases, and at a pore size of $40 \mu \mathrm{m}$, for ethanol-water mixtures, the mole fraction of ethanol increased by about $5 \%$. The percent increase in the methanol concentration was still less than $1 \%$ at this pore size. At $5 \mu \mathrm{m}$, for ethanolwater mixtures, the predicted ethanol concentration increased by about $60 \%$, and the methanol concentration increased by about $10 \%$.

\subsection{Model Predictions for Aqueous and Non-Aqueous Systems}

The model was used to predict the VLE of four solutions at pore sizes 40 and $5 \mu \mathrm{m}$ : ethanol-water, propanol-water, methanol-isopropanol and ethanol-n-octane. Figure 4.2 shows the VLE of ethanol-water compositions predicted by the model at $60^{\circ} \mathrm{C}$. The vapor mole fraction of ethanol showed a $3 \%$ increase in $40 \mu \mathrm{m}$ pores. The deviation in the VLE increased as the pore sizes decreased, and in $5 \mu \mathrm{m}$ pores, a $40 \%$ increase in ethanol mole fraction was predicted by the model. Similar changes in the VLE were observed for propanol-water mixtures in Figure 4.3. The increase in the vapor mole fraction of propanol was calculated to be $6-7 \%$ in $40 \mu \mathrm{m}$ pores compared with $40-50 \%$ increase in $5 \mu \mathrm{m}$ pores. 


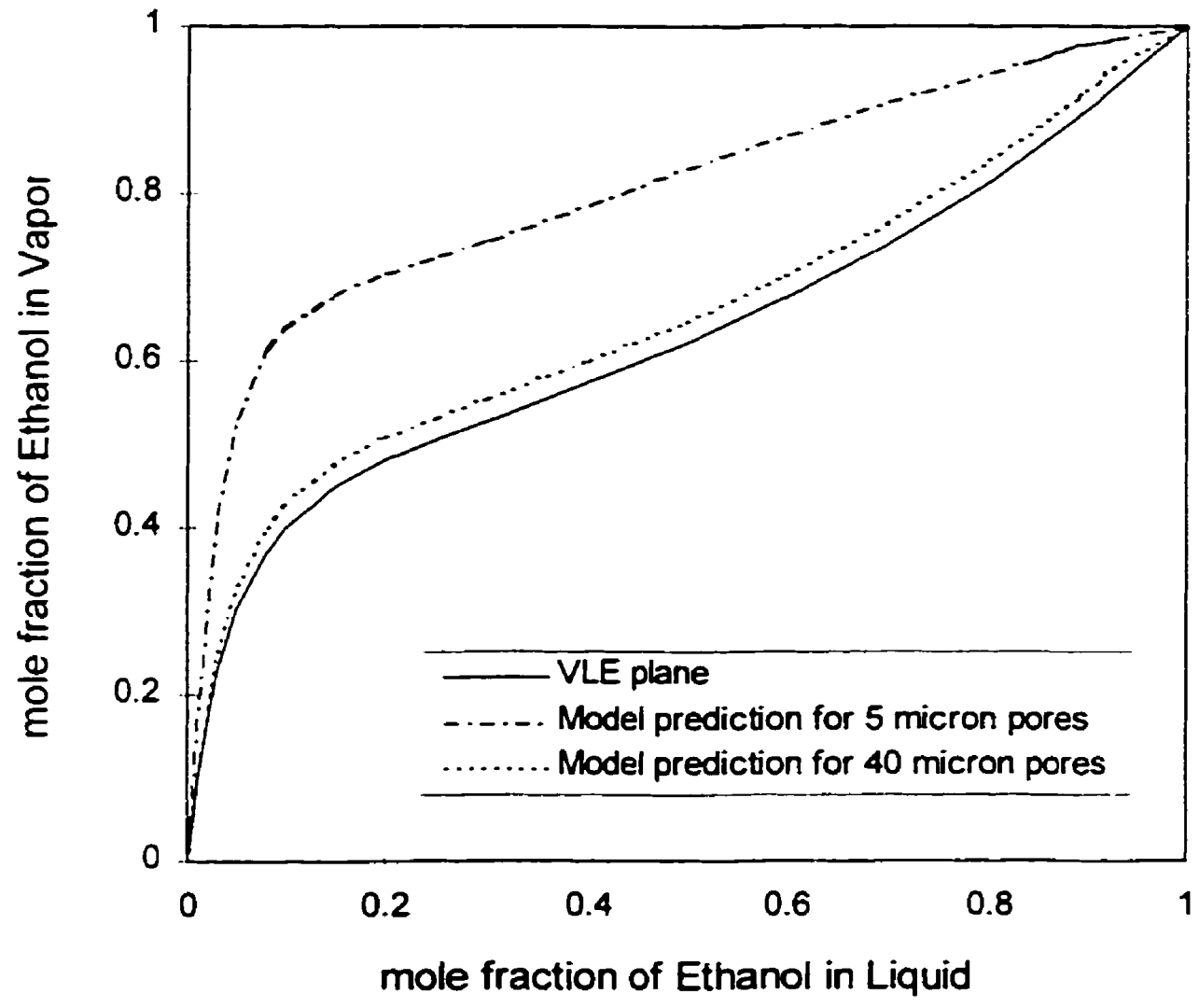

Figure 4.2: Model Prediction for VLE of Ethanol-Water Mixtures at $60^{\circ} \mathrm{C}$ 


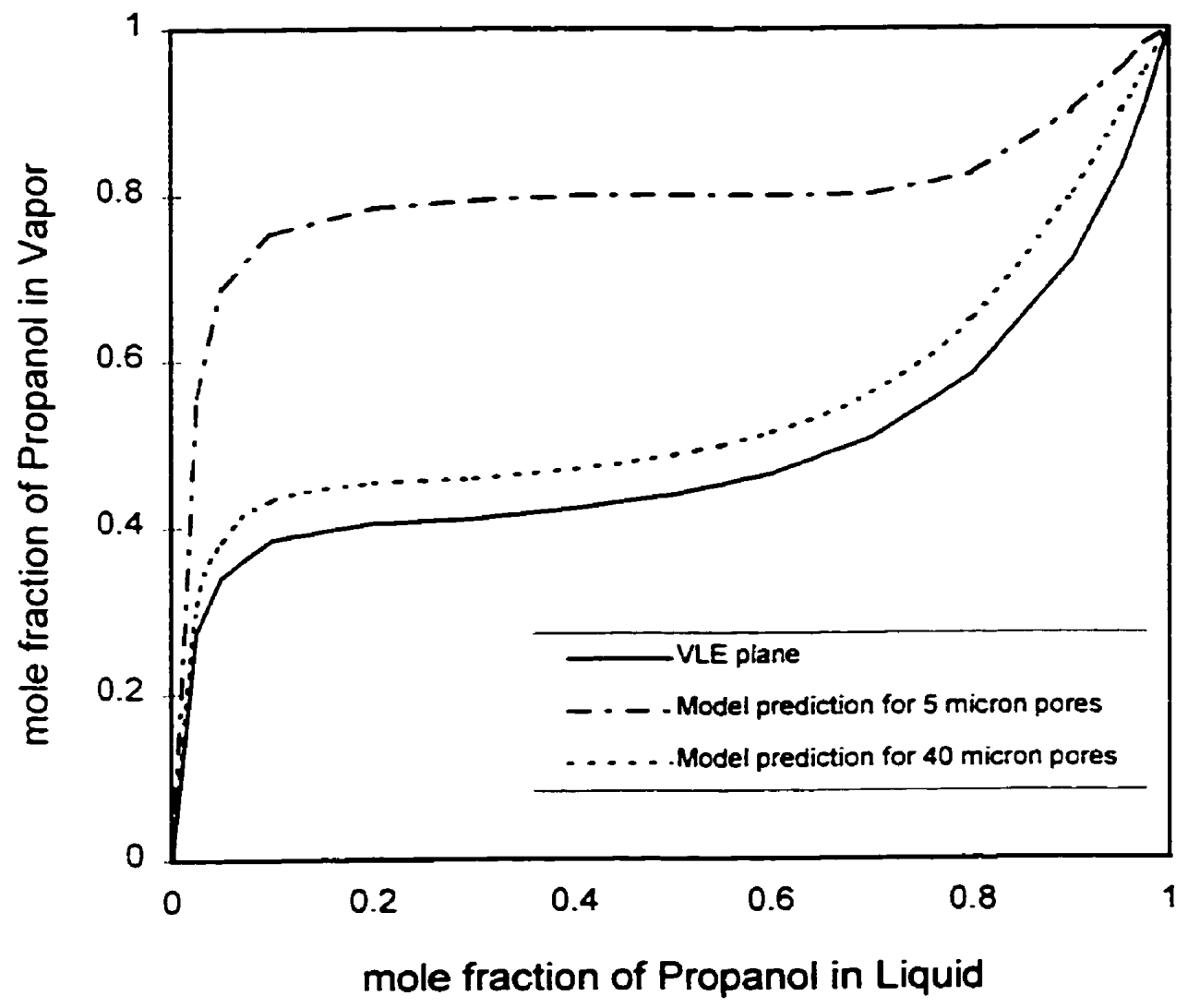

Figure 4.3: Model Prediction for Propanol-Water Mixtures at $60^{\circ} \mathrm{C}$ 
The model prediction for methanol-isopropanol and ethanol-octane mixtures showed less pronounced changes in the VLE than those for aqueous solutions (Figures 4.4 and 4.5 ). Since capillary action is a function of surface tension, the curved surface effect on the non-aqueous systems was expected to be less significant than on aqueous systems. Less than $1 \%$ change was predicted for both compounds in $40 \mu \mathrm{m}$ pores, and only $4-5 \%$ change was predicted in $5 \mu \mathrm{m}$ pores. From these figures, one can conclude that in order to alter the equilibrium of methanol-isopropanol and ethanol-n-octane mixtures, very fine pores are required.

\subsection{Actual Pore Sizes of the Porous Media}

In order to compare model predictions with the experimental results, the actual pore sizes and thus the diameter of the curved liquid surface in the sintered metal and fritted glass plates were estimated. Wong (1997) measured the actual pore sizes using a Scanning Electron Microscope (SEM), and her results showed that the stated nominal pore sizes given by the manufacturers were one order of magnitude smaller than the actual pore diameters measured under the microscope (1997). Although the values given by manufacturers may be adequate to predict what size particles will be trapped in the tortuous pores, the nominal values are inappropriate to predict the surface of the liquid filling the pores. In addition, the pores were found to be irregular in shape according to the SEM photographs presented in Wong's thesis (Figures 4.6 and 4.7 ). 


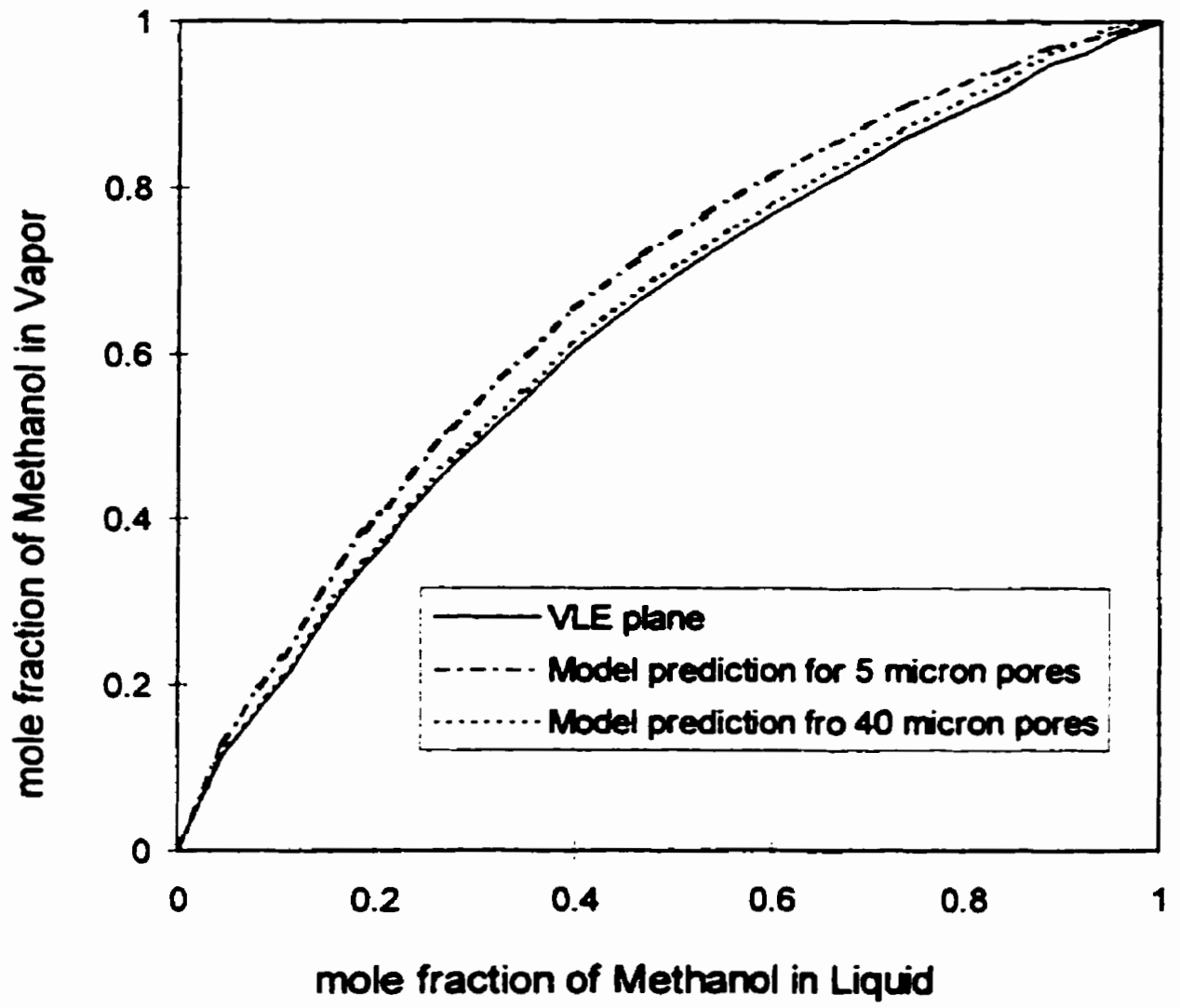

Figure 4.4: Model Prediction for Methanol-Isopropanol Mixtures at $55^{\circ} \mathrm{C}$ 


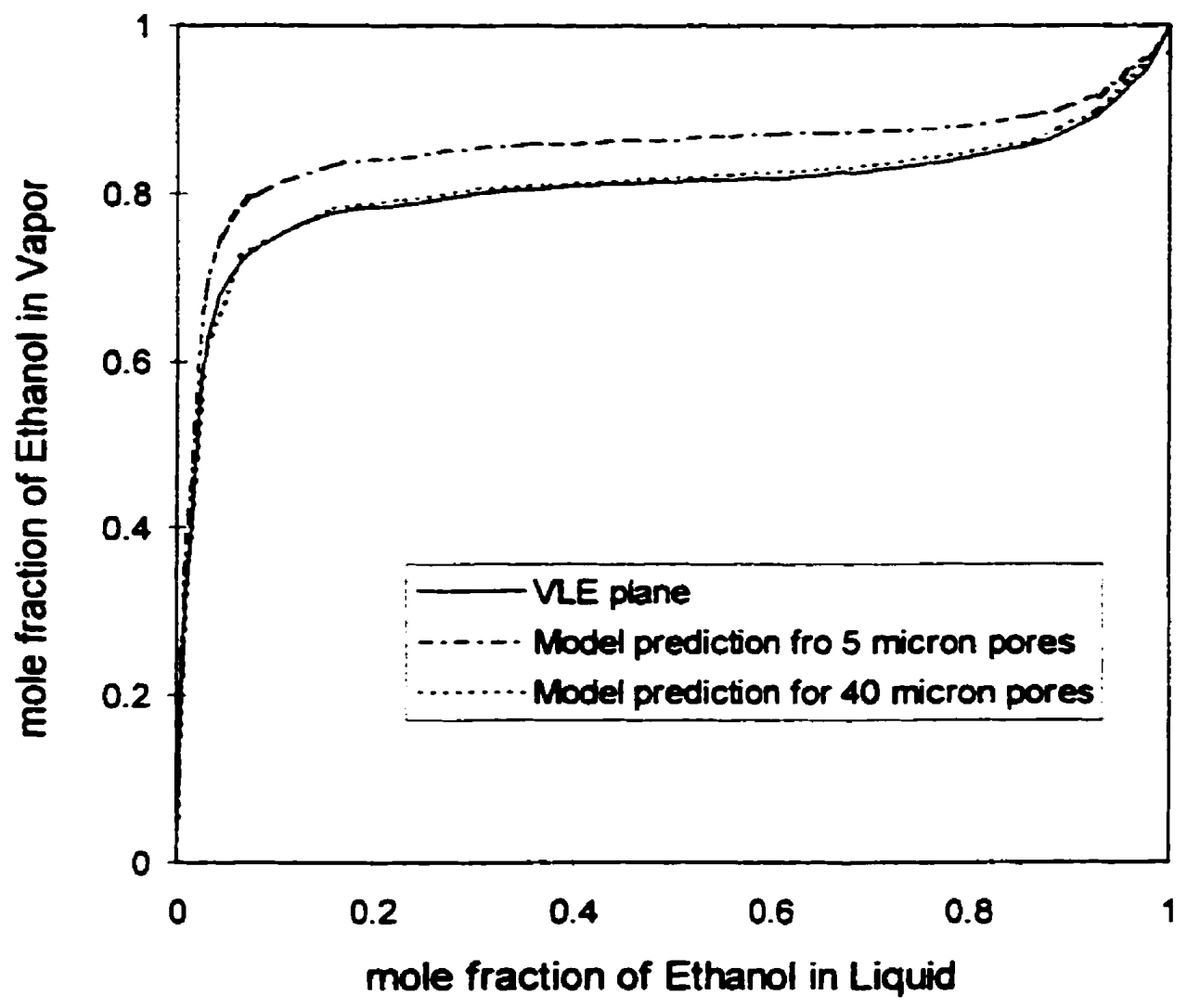

Figure 4.5: Model Prediction for Ethanol-n-Octane Mixtures at $75^{\circ} \mathrm{C}$ 


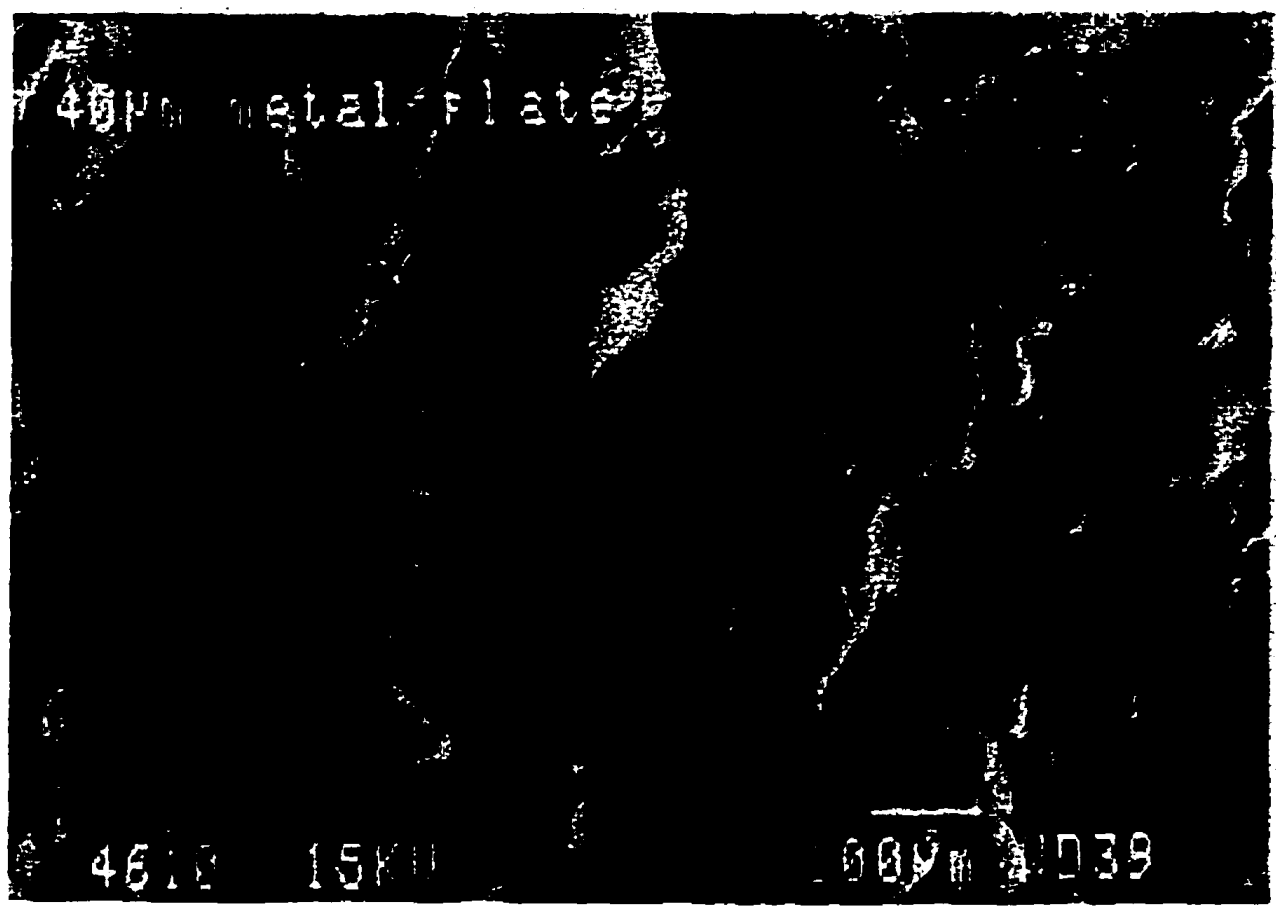

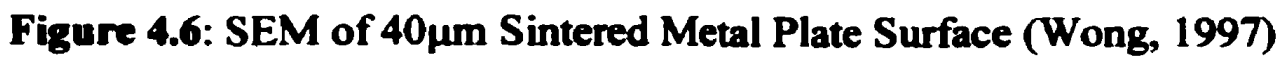

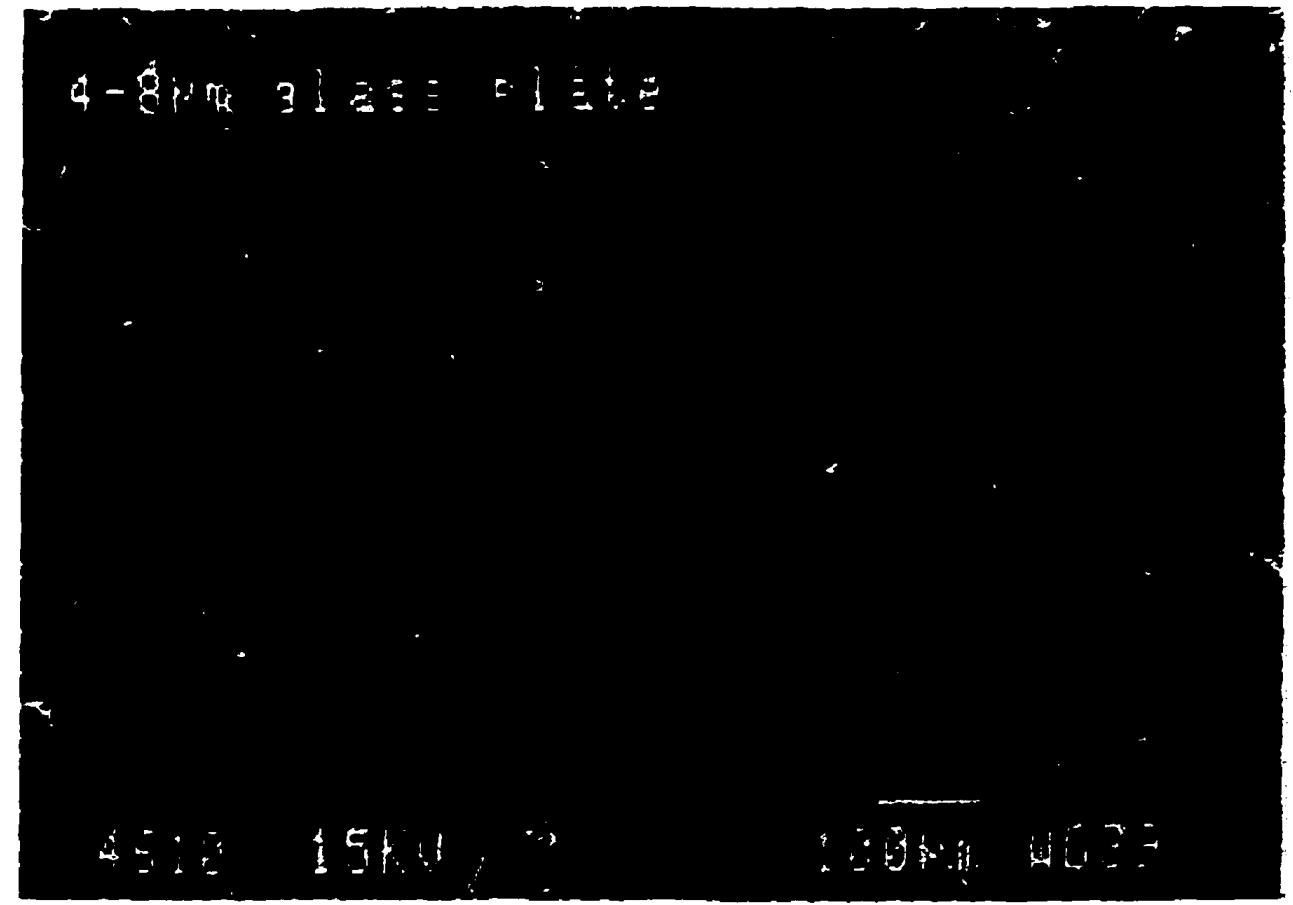

Figure 4.7: SEM of 4-8 $\mu \mathrm{m}$ Fritted Glass Plate Surface (Wong, 1997) 
Table 4.1 summarizes the measured pore sizes of sintered metal and fritted glass plates measured by Wong (1997). Based on her measurements, the diameter of curvature at the liquid-vapor interface was estimated as follows. When liquid is pippetted onto a 4$8 \mu \mathrm{m}$ fritted glass plate, the liquid fills the space between the glass beads. Its top surface would have a diameter of $27 \pm 9 \mu \mathrm{m}$. which is equal to the measured pore diameter (Figure 4.8 ).

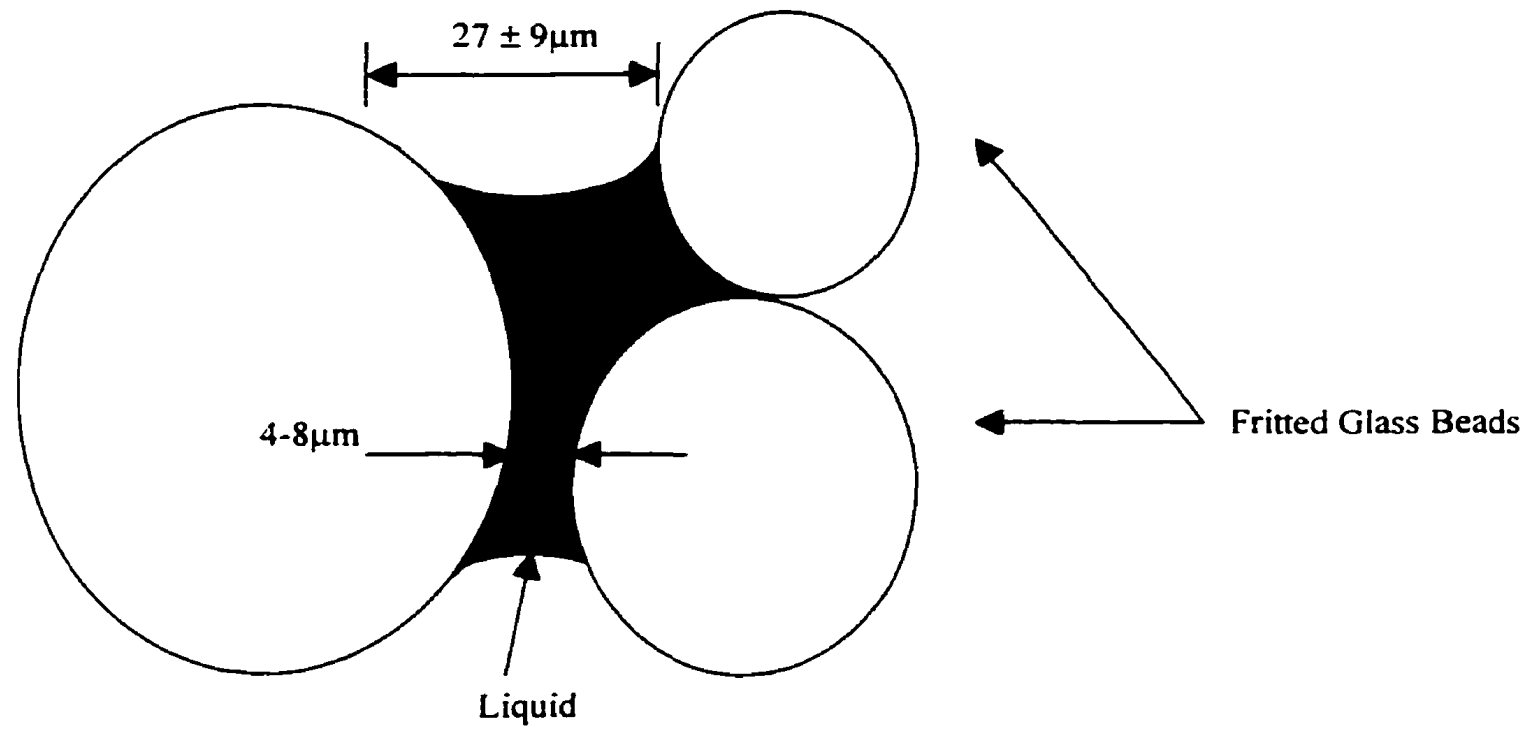

Figure 4.8: Schematic of Cross-Section of 4-8 $\mu \mathrm{m}$ Fritted Glass Plate

Table 4.1: Stated Nominal and Measured Pore Sizes (Wong, 1997)

\begin{tabular}{|l|c|}
\hline Stated Nominal Pore Size & Measured Pore Diameter \\
\hline Sintered Metal Plate, $40 \mu \mathrm{m}$ & $84 \pm 40(\mu \mathrm{m})$ \\
\hline Fritted Glass Plate, $4-8 \mu \mathrm{m}$ & $27 \pm 9(\mu \mathrm{m})$ \\
\hline
\end{tabular}


Not only the pore sizes, but the contact angle between the liquid and solid in such porous media had to be estimated. Knowing that the fritted glass plates were made of spherical glass beads, the contact angle between the liquid and the beads is expected to be greater than the contact angle between the liquid and the solid in cylindrical pores (i.e. capillaries). Figure 4.9 shows the difference in the contact angles between glass beads and capillaries with the same pore diameters and made of the same material. Having considered the measured pore diameters and the relative contact angles. the actual pore diameter in $40 \mu \mathrm{m}$ nominal sintered metal and $4-8 \mu \mathrm{m}$ nominal fritted glass plates were estimated to be $100 \mu \mathrm{m}$ and $40 \mu \mathrm{m}$ respectively. These values were used in the model predictions. and the results were compared with the experimental values.

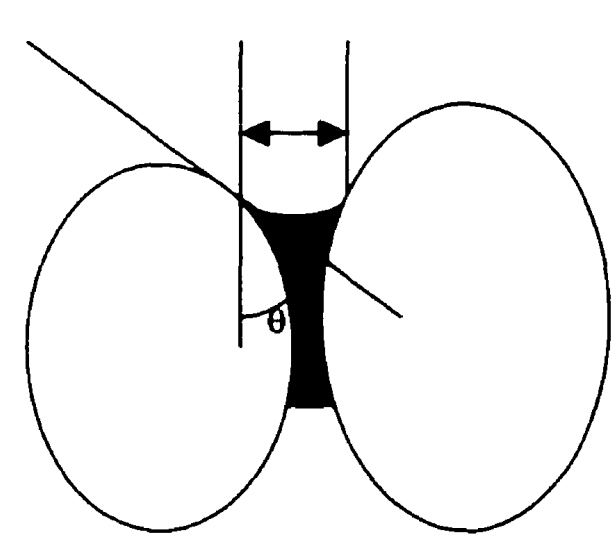

(a)

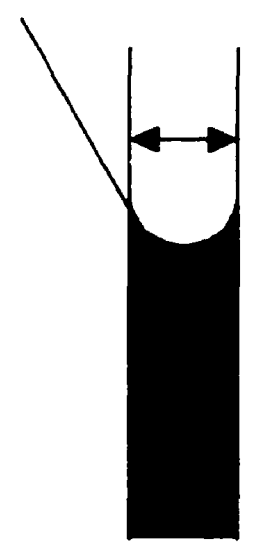

(b)

Figure 4.9: Schematic of Contact Angles in Different Shapes of Porous Media (a) Glass Beads, (b) Capillaries 


\subsection{Comparison of Model Predictions with Experimental Results}

The VLE of ethanol-water mixtures in sintered metal plates is shown in Figure 4.10. Using the estimated diameter of the curvature of $100 \mu \mathrm{m}$, the model predicted a marginal increase in the ethanol mole fraction in vapor phase. The experimental results also showed less than $2 \%$ increase in the vapor mole fractions. The model-predicted VLE in fritted glass plates was predicted to increase by $4 \%$ when the estimated diameter of $40 \mu \mathrm{m}$ was used in the model (Figure 4.11). This model prediction was compared with the experimental results obtained by Wong (1997) and showed good agreement.

The comparison for propanol-water in fritted glass plate is shown in Figure 4.12. The experimental results showed good agreement with the predicted increase of $7 \%$ in the propanol mole fraction in the vapor phase. From Figures 4.11 and 4.12 , one may conclude that the $\mathrm{SS}_{\text {mod }}$ model predictions agree well with the experimental results. In comparison, both Kelvin and Yeh equations predicted no change in the VLE of given solutions at this pore size due to their limitations in describing the behavior of real fluids.

The model predictions for binary alcohol mixtures, methanol-isopropanol and ethanol-n-octane were compared with experimental results in Figure 4.13 and 4.14. Using the estimated pore sizes of $100 \mu \mathrm{m}$ for sintered metal and $40 \mu \mathrm{m}$ for fritted glass plates, the model predicted less than $1 \%$ change in the vapor phase compositions in both systems indicating that the liquid surface in such media was flat rather than curved. 


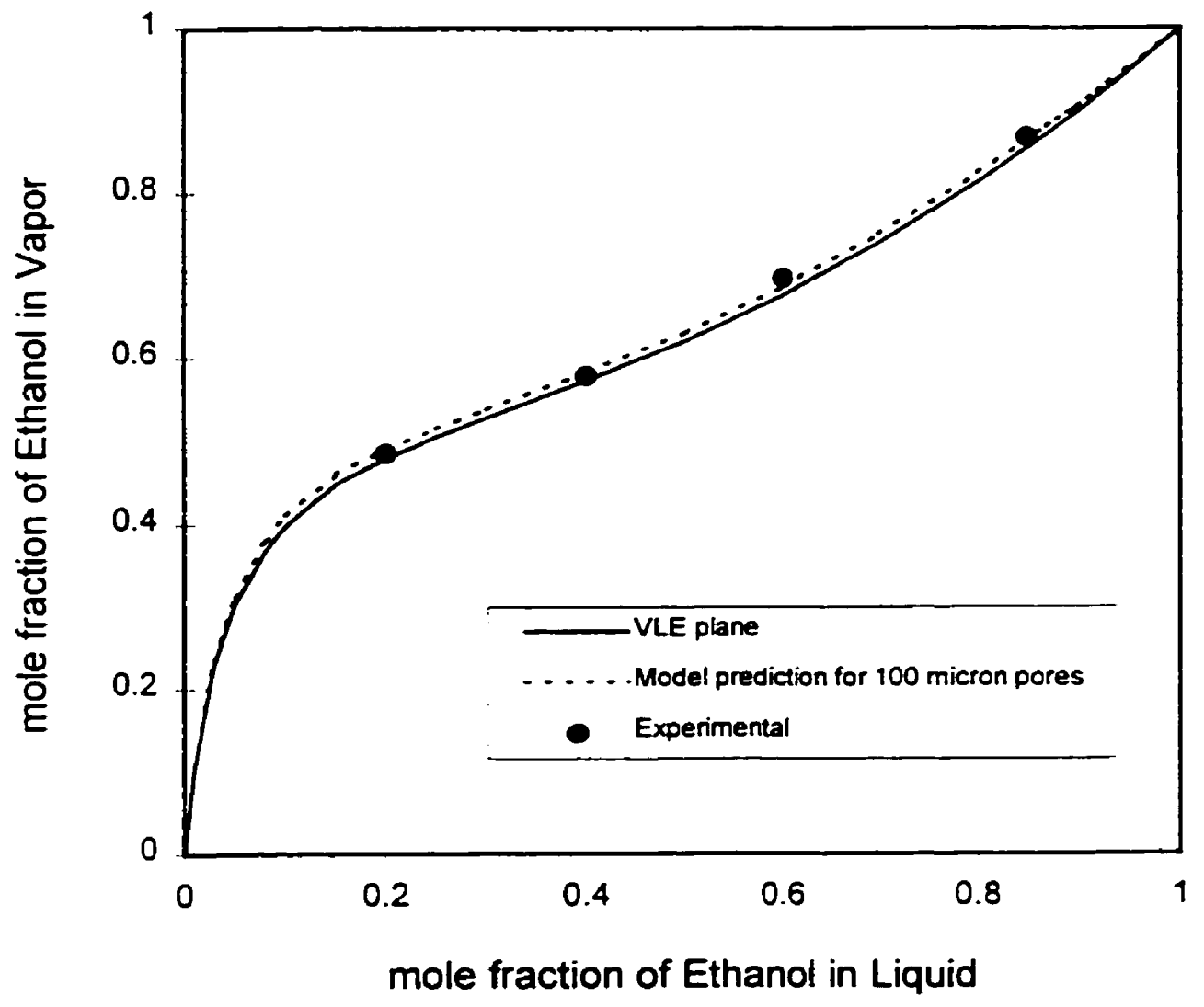

Figure 4.10: VLE of Ethanol-Water at $60^{\circ} \mathrm{C}$ in Sintered Metal Plate 


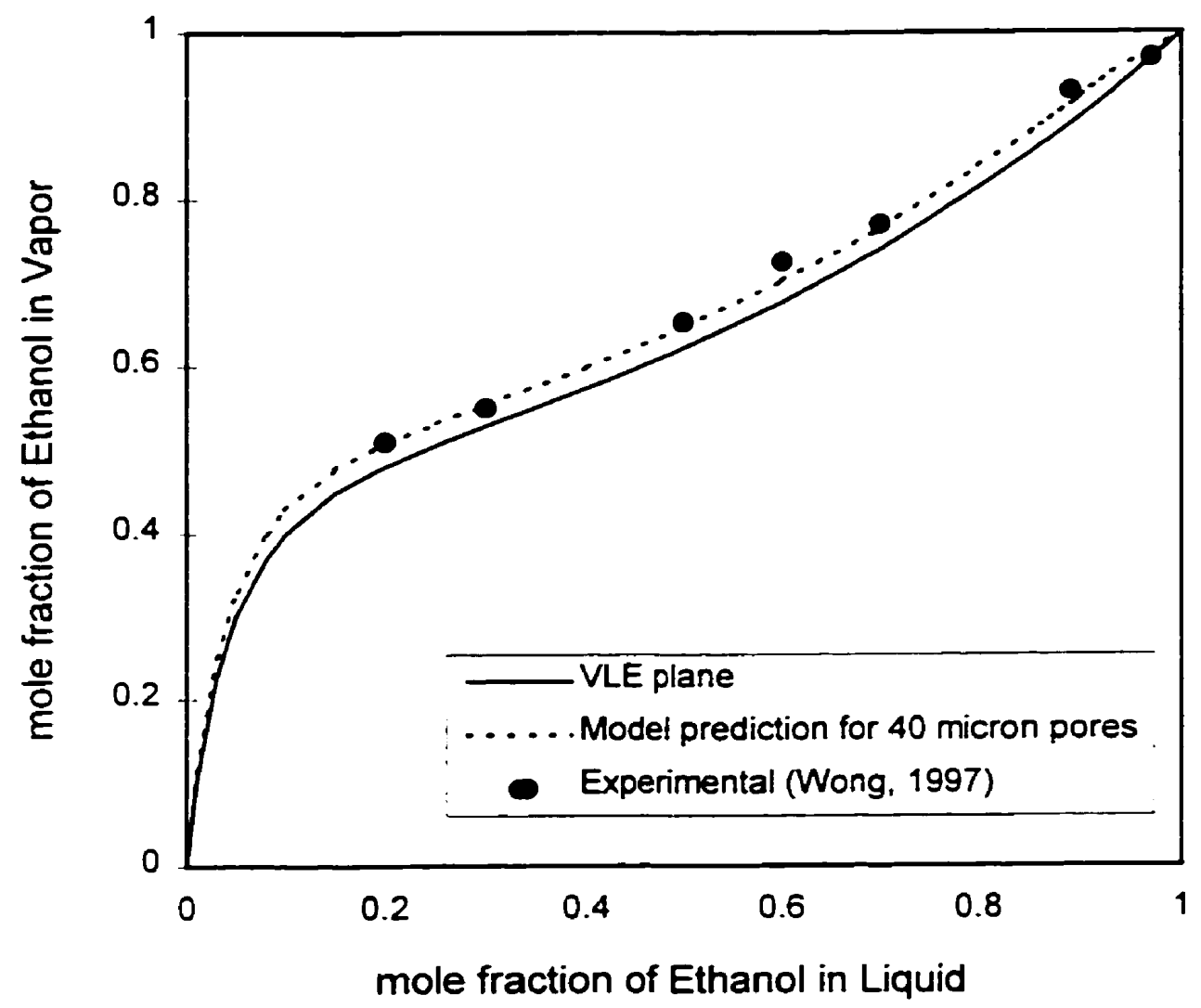

Figure 4.11: VLE of Ethanol-Water at $60^{\circ} \mathrm{C}$ in Fritted Glass Plate 


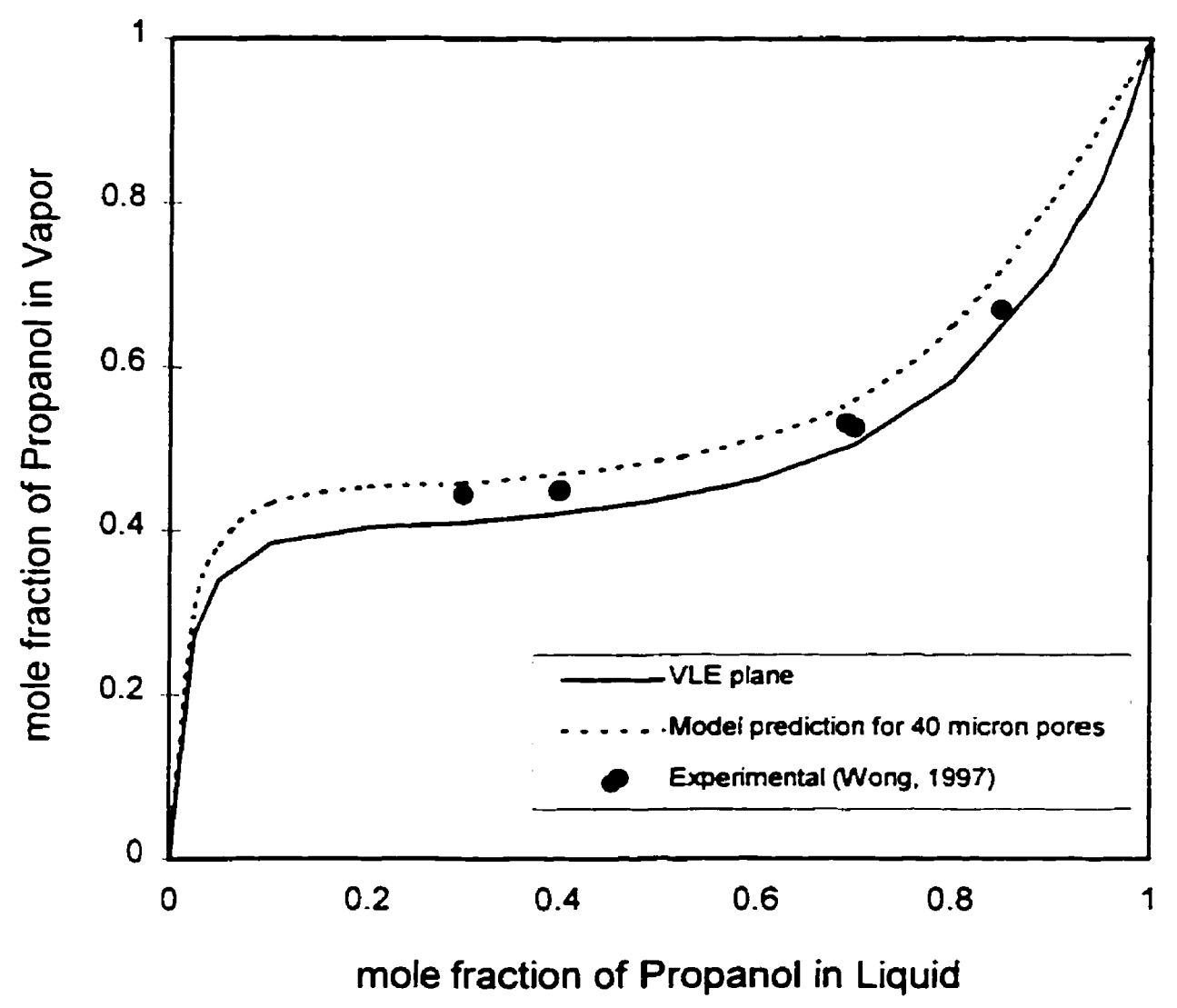

Figure 4.12: VLE of Propanol-Water at $60^{\circ} \mathrm{C}$ in Fritted Glass Plate 


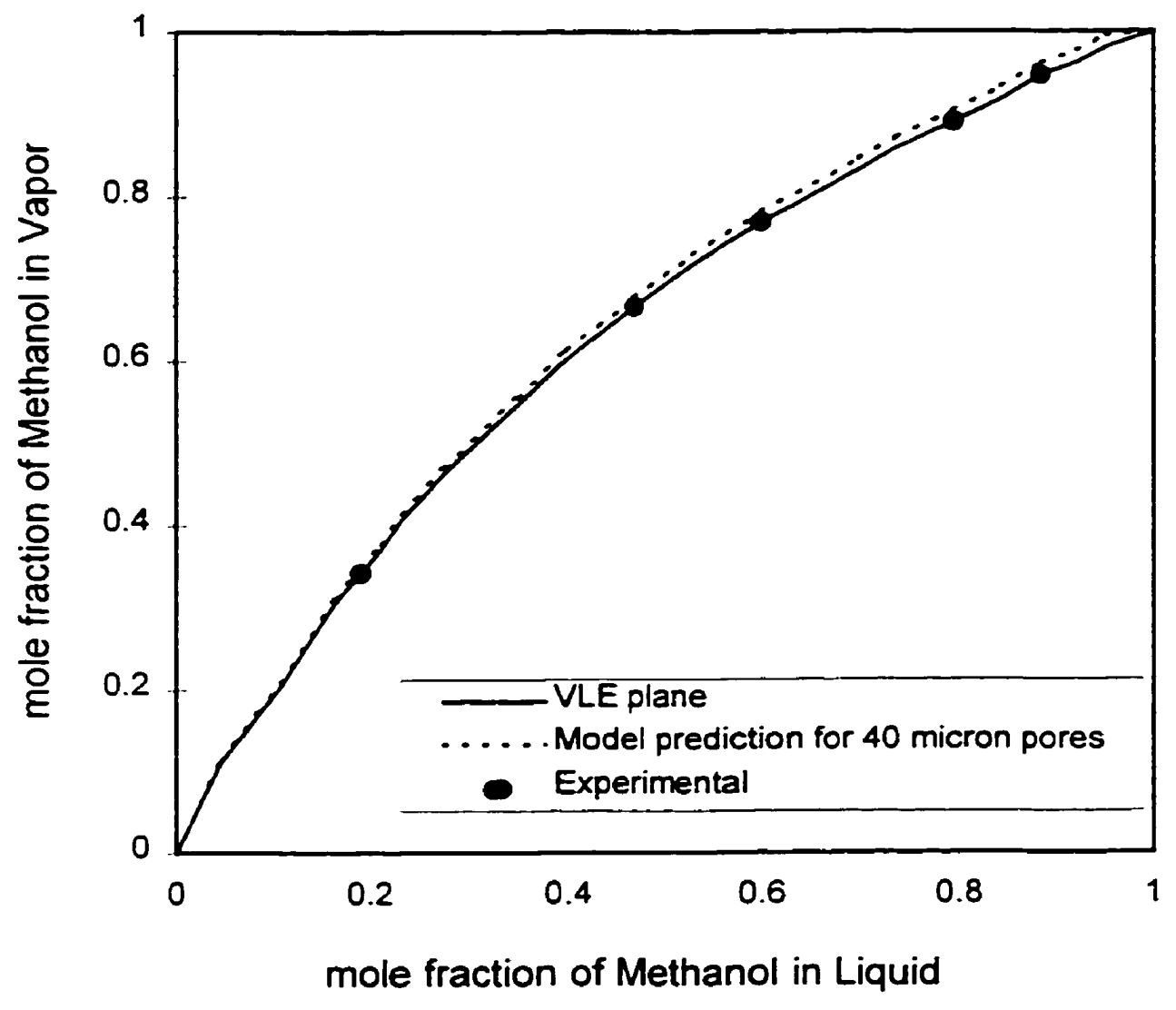

Figure 4.13: VLE of Methanol-Isopropanol at $55^{\circ} \mathrm{C}$ in Fritted Glass Plate 


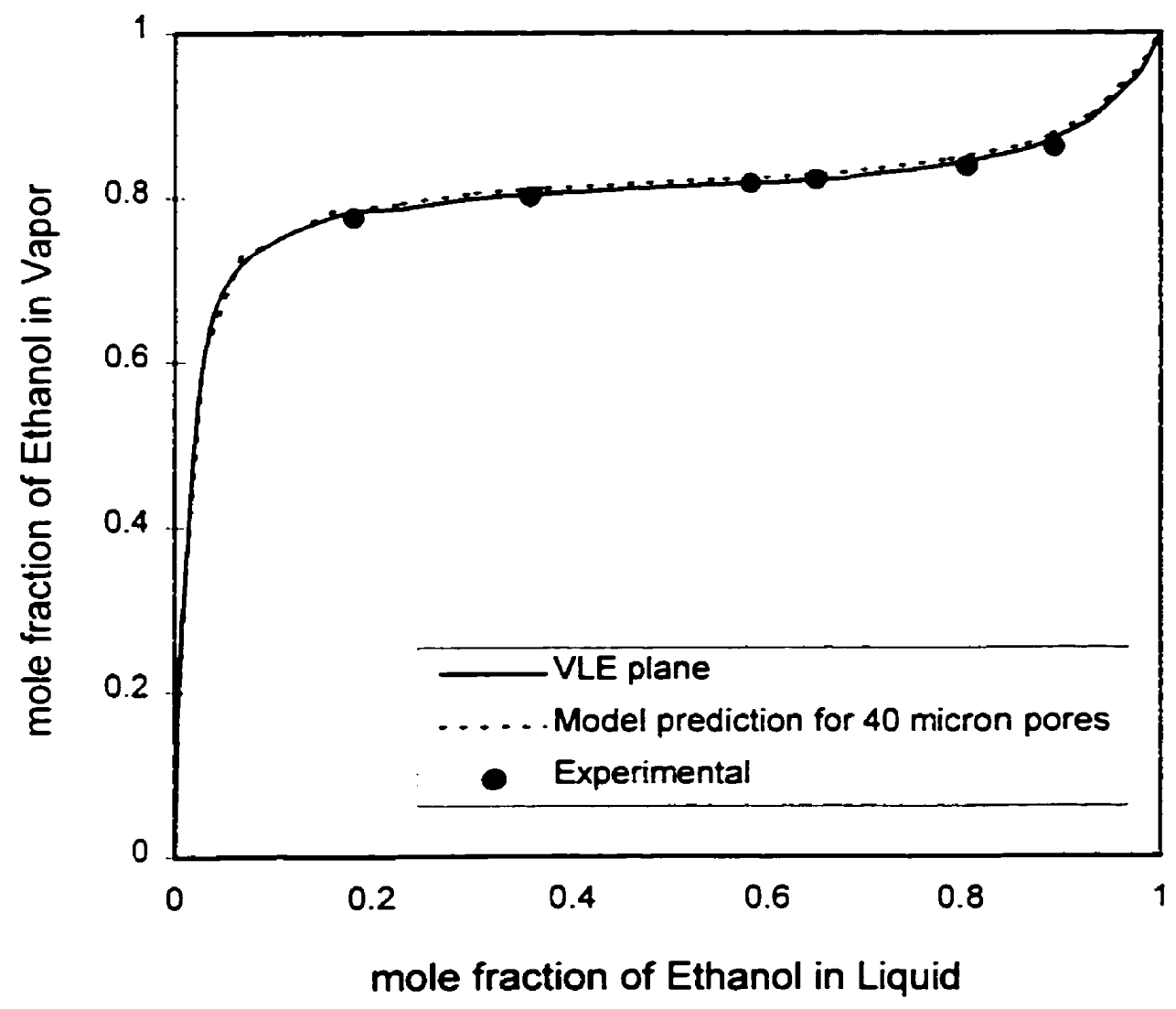

Figure 4.14: VLE of Ethanol-n-Octane at $75^{\circ} \mathrm{C}$ in Fritted Glass Plate 


\subsection{CONCLUSIONS AND RECOMMENDATIONS}

The development of the $\mathrm{SS}_{\bmod }$ model provided a method for estimating the vapor and liquid equilibria (VLE) in porous media as a function of pore sizes. The model was validated by conducting a series of experiments using sintered metal and fritted glass plates as porous media. The actual pore diameter in chosen porous media was estimated, and the model prediction showed excellent agreement with the experimental results. On the other hand, the Kevin and Yet et al. (1991b) equations predicted vapor pressures that were orders of magnitude greater the experimental values.

The VLE of aqueous solutions showed a $4-6 \%$ increase in the vapor phase concentration in fritted glass plates. The liquid surface modification effect was not visible with the non-aqueous solutions due to the pores that were too big to provide sufficient curvature at the liquid-vapor interface.

The main limitation on the experimental procedure was the unavailability of porous media with very fine pores. The nominal sizes claimed by manufacturers do not correspond to the actual pore diameter of liquid. Thus, porous media with finer and more uniform pores should be found to provide more pronounced changes in the vapor phase concentrations. This project could be further improved by testing additional binary or tertiary systems whose components are all detected by the GC and whose model prediction indicates a large deviation in the VLE with and without porous media.

Since the difference in the vapor samples with and without porous media is small, the sample analysis has to be accurate. For aqueous alcohol systems, the alcohol concentration was calculated by using a calibration curve generated from literature values 
(Section 3.2.3). The increase in the peak area was directly converted to the increase in the mole fraction. For the methanol-isopropanol and ethanol-n-octane systems whose components were both detected by the GC, and the vapor mole fractions were directly calculated using $\mathrm{K}$ factors. An additional variable which would be of interest would be the vial pressure. Future experiments might benefit from its monitoring. 


\subsection{NOMENCLATURE}

F solid-liquid interfacial force

P pressure

$r$ radius

R universal gas constant

$T$ temperature

$\mathrm{V}$ molar volume

$x \quad$ molar fraction

$z$ compressibility

Z compressibility ratio

Greek Letters

$\varepsilon \quad$ dielectric constant

$\theta$ contact angle

$\mu \quad$ chemical potential

$\sigma \quad$ surface tension

$\chi \quad$ relative pressure

Subscripts

$\begin{array}{ll}\text { av } & \text { average ratio } \\ \text { curv } & \begin{array}{l}\text { curved liquid surface } \\ \text { d }\end{array} \\ \text { dew point } \\ \text { dis } & \text { dispersion } \\ \text { L } & \text { liquid } \\ \text { MIX } & \text { mixed } \\ \text { o } & \text { bulk } \\ \text { pol } & \text { polar } \\ \text { r } & \text { reduced properties } \\ \text { v } & \text { vapor }\end{array}$




\subsection{REFERENCES}

Atkins, P.W., Physical Chemistry, W. H. Freeman and Company, San Francisco, 1982.

Béland, D., Personal Communication (1998).

Boucher, E. A., "Capillary Phenomena", J. Chem. Soc., Faraday Trans. L 80 (1984) 3295-3305.

Defay, R., I. Prigogine, A. Bellemans and D. H. Everett, Surface Tension and Adsorption, John Wiley and Sons, New York, 1966.

Gmehling, J. and U. Onken, Vapor-Liquid Equilibrium Data Collection, Dechema, Deutsche Gesellschaft fur Chemisches Apparatewesen, 1981.

Kuz, V. A., "Thermodynamic Vapor Pressure Equation. Triple and Critical Point Applications. Prediction of a Linear Logarithmic Relation between Surface Tension and Latent Heat of Evaporation", Fluid Phase Equilibria, 66 (1991) 113-124.

McNair, H. M. and J. M. Miller, Basic Gas Chromatography, John Willey \& Sons Inc., 1997. 
Perry, R. H., ed., Perry's Chemical Engineers' Handbook, $7^{\text {th }}$ ed., McGraw Hill Book Company, 1997.

Sandoval, G., G. Wilczek-Vera and J. H. Vera, "Prediction of Ternary Vapor-Liquid Equilibria with the PRSV Equation of State", Fluid Phase Equilibria, 52 (1989) 119-126.

Shapiro, A. A. and E. H. Stenby, "Kelvin Equation for a Non-Ideal Multicomponent Mixture", Fluid Phase Equilibria, 134 (1997) 87-101.

Stryjek, R. and J. H. Vera, "PRSV: An Improved Peng-Robinson Equation of State for Pure Compounds and Mixtures", The Canadian Journal of Chemical Engineering, 64 (1986) 323-333.

Truong, J. and P. C. Wayner Jr., "Effect of Capillary and van der Waals Dispersion Forces on the Equilibrium Profile of a Wetting Liquid: Theory an Experiment", $J$. Chem. Phys., 87 (1987) 4180-4188.

Varian, Genesis Headspace Autosampler, Operator's Manual, Varian Associates Inc., 1991.

Wong, N. S. J., "The Effects of Capillary Plates on Vapor-Liquid Equilibrium in Aqueous Alcohol Systems", Master Thesis (Chem. Eng.), McGill University, Montreal, Canada (1997) 
Yeh, G. C., B. V. Yeh, B. J. Ratigan, S. J. Correnti, M. S. Yeh, D. W. Pitakowski,

W. Fleming, D. B. Ritz and J. A. Lariviere, "Separation of Liquid Mixtures by Capillary Distillation", Desalination, 81 (1991a) 129-160.

Yeh, G. C., B. V. Yeh, S. T. Schmidt, M. S. Yeh, A. M. McCarthy and W. J. Celenza, "Vapor-Liquid Equilibrium in Capillary Distillation", Desalination, 81 (1991b) 161-187. 
APPENDIX A: List of Equations 


\section{Antoine Equation}

$\log P_{v, 0}=A-\frac{B}{T+C} \quad\left(P_{v, 0}\right.$ is in bar and $\mathrm{T}$ is in $\left.\mathrm{K}\right)$

\section{Vapor Pressure}

$$
\begin{aligned}
& P_{v, 0}^{\text {system }}=x_{1} \gamma_{1} P_{1, v, 0}+x_{2} \gamma_{2} P_{2, v, 0} \\
& \ln \gamma_{1}=-\ln \left(x_{1}+\Lambda_{12} x_{2}\right)+x_{2}\left(\frac{\Lambda_{12}}{x_{1}+\Lambda_{12} x_{2}}-\frac{\Lambda_{21}}{\Lambda_{21} x_{1}+x_{2}}\right) \text { for binary mixtures } \\
& \ln \gamma_{2}=-\ln \left(x_{2}+\Lambda_{21} x_{1}\right)-x_{1}\left(\frac{\Lambda_{12}}{x_{1}+\Lambda_{12} x_{2}}-\frac{\Lambda_{21}}{\Lambda_{21} x_{1}+x_{2}}\right)
\end{aligned}
$$

\section{PRSV equation of state}

$$
\begin{aligned}
P=\frac{R T}{v-b} & -\frac{a}{v^{2}+2 b v-b^{2}} \\
a_{i} & =\frac{0.45723553 R^{2} T_{c i}^{2}}{P_{c i}}\left[1+k k_{1}\left(1-\left(\frac{T}{T_{c i}}\right)^{1 / 2}\right)\right]^{2} \\
k_{0 i} & =0.378893+1.4897153 \omega_{i}-0.17131848 \omega_{i}^{2}+0.0196554 \omega_{i}^{3} \\
k k_{i} & =k_{o i}+k A_{i}\left(1+\left(\frac{T}{T_{c i}}\right)^{0.5}\right)\left(0.7-\frac{T}{T_{c i}}\right) \\
b_{i}= & 0.077796074 \frac{R T_{c i}}{P_{c i}} \\
a & =x_{1}^{2} a_{1}+x_{2}^{2} a_{2}+2 x_{1} x_{2} \sqrt{a_{1} a_{2}}\left[1-\overline{k_{12}}-x_{1} \Delta k_{12}-x_{2} \Delta k_{21}-l_{12}\left(x_{1}-x_{1}^{2}+x_{2}-x_{2}^{2}\right)\right]
\end{aligned}
$$




$$
\begin{aligned}
& b=x_{1} b_{1}+x_{2} b_{2} \\
& \overline{k_{12}}=\frac{k_{12}+k_{21}}{2} \\
& \Delta k_{12}=k_{12}-\overline{k_{12}} \\
& \Delta k_{21}=k_{21}-\overline{k_{12}}
\end{aligned}
$$

\section{Volume explicit PRSV equation}

$$
\begin{aligned}
& v^{3}+\left(b-\frac{R T}{P}\right) v^{2}+\left(\frac{a}{P}-2 b \frac{R T}{P}-3 b^{2}\right) v+\left(b^{3}+b^{2} \frac{R T}{P}-\frac{a b}{P}\right)=0 \\
& p=\frac{1}{3}\left(b-\frac{R T}{P}\right) \\
& q=\frac{1}{3}\left(\frac{a}{P}-2 b \frac{R T}{P}-3 b^{2}\right) \\
& r=\frac{1}{2}\left(b^{3}+b^{2} \frac{R T}{P}-\frac{a b}{P}\right) \\
& \alpha=q-p^{2} \\
& \beta=p^{3}-\frac{3}{2} p q+r \\
& R=\beta^{2}+\alpha^{3} \\
& \text { If } \mathrm{R} \geq 0 \quad v=M+N-p \\
& M=\sqrt[3]{-\beta+\sqrt{R}} \\
& N=\sqrt[3]{-\beta-\sqrt{R}}
\end{aligned}
$$




$$
\text { If } \begin{aligned}
\mathrm{R}<0 \quad v_{1} & =2 \sqrt{-\alpha} \cos \left(\frac{\phi}{3}\right)-p \\
v_{2} & =2 \sqrt{-\alpha} \cos \left(\frac{\phi}{3}+\left(\frac{2}{3}\right) \pi\right)-p \\
v_{3} & =2 \sqrt{-\alpha} \cos \left(\frac{\phi}{3}+\left(\frac{4}{3}\right) \pi\right)-p \\
\phi & =\operatorname{arc~} \cos \frac{-\beta}{\sqrt{-\alpha^{3}}}
\end{aligned}
$$

\section{Compressibility erolicit PRSV}

$z=\frac{v}{v-b}-\frac{a v}{R T\left(v^{2}+2 b v-b^{2}\right)}$

\section{Fugacity coefficient}

$$
\begin{aligned}
\ln \phi_{t}= & \frac{b_{i}}{b}(z-1)-\ln \left(z-B^{\cdot}\right)+\frac{A^{\bullet}}{2 \sqrt{2} B^{*}}\left(\frac{b_{i}}{b}-\delta_{i}\right) \ln \frac{z+B^{\bullet}(1+\sqrt{2})}{z+B^{\bullet}(1-\sqrt{2})} \\
\delta_{i} & =\frac{2 a_{i}^{1 / 2}}{a} \sum_{j} x_{j} a_{j}^{1 / 2}\left(1-k_{i j}\right) \\
A^{\cdot} & =\frac{a P}{R^{2} T^{2}} \\
B^{\cdot} & =\frac{b P}{R T}
\end{aligned}
$$


59

7. Vapor and liquid equilibrium

$$
y_{i}=\frac{x_{i} \phi_{i}{ }^{L}}{\phi_{i}{ }^{2}}
$$

8. Surface tension (Perry's, p2-372, $7^{\text {th }}$ ed.)

For non-aqueous: $\sigma_{m i x}=\sum \sum \rho_{m i x}^{2}\left(\frac{x_{i}}{\rho_{L i, p u r e}}\right)\left(\frac{x_{j}}{\rho_{L j, p u r e}}\right)\left(\sigma_{i, p u r e} \sigma_{j, p u r e}\right)^{2}$

For aqueous: $\quad \sigma_{m \dot{x}}^{1 / 4}=\psi_{w} \sigma_{w}^{1 / 4}+\left(1-\psi_{w}\right) \sigma_{o}^{1 / 4}$

where $\log \frac{\left(\psi_{w}\right)^{q}}{\psi_{w}}=\log \left[\frac{\left(x_{w} V_{w}\right)^{q}}{x_{0} V_{0}}\left(x_{w} V_{w}+x_{0} V_{0}\right)^{1-q}\right]+\frac{0.441 q}{T}\left(\frac{\sigma_{0} V_{o}^{2 / 3}}{q}-\sigma_{o} V_{0}^{2 / 3}\right)$

$$
\sigma_{\text {,.pure }}=\left(\rho_{\text {LAp... }}[P]\right)^{4}
$$

9. y/vo for modified Shapiro-Stenby equation(SS med Model)

$$
\begin{aligned}
& P_{c u r v}=P_{L}-P_{v}=-\frac{2 \sigma \cos \theta}{r_{c u r v}} \\
& P_{\text {curve }}^{\cdot} r_{\text {ur }}^{\cdot}=P_{\text {carr }} r_{\text {care }} \quad \text { (assuming constant } \theta \text { and ideal gas) } \\
& \frac{y}{y_{0}}=\frac{P_{\mathrm{v}}}{P_{\mathrm{v}, 0}}=1+\left(\frac{r_{\text {cor }}}{r_{\text {nov }}}\right) \frac{P_{\text {ave }}^{\prime}}{P_{v}}
\end{aligned}
$$




\section{Algorithm for modified Shapiro-Stenby equation (SS-od Moded)}

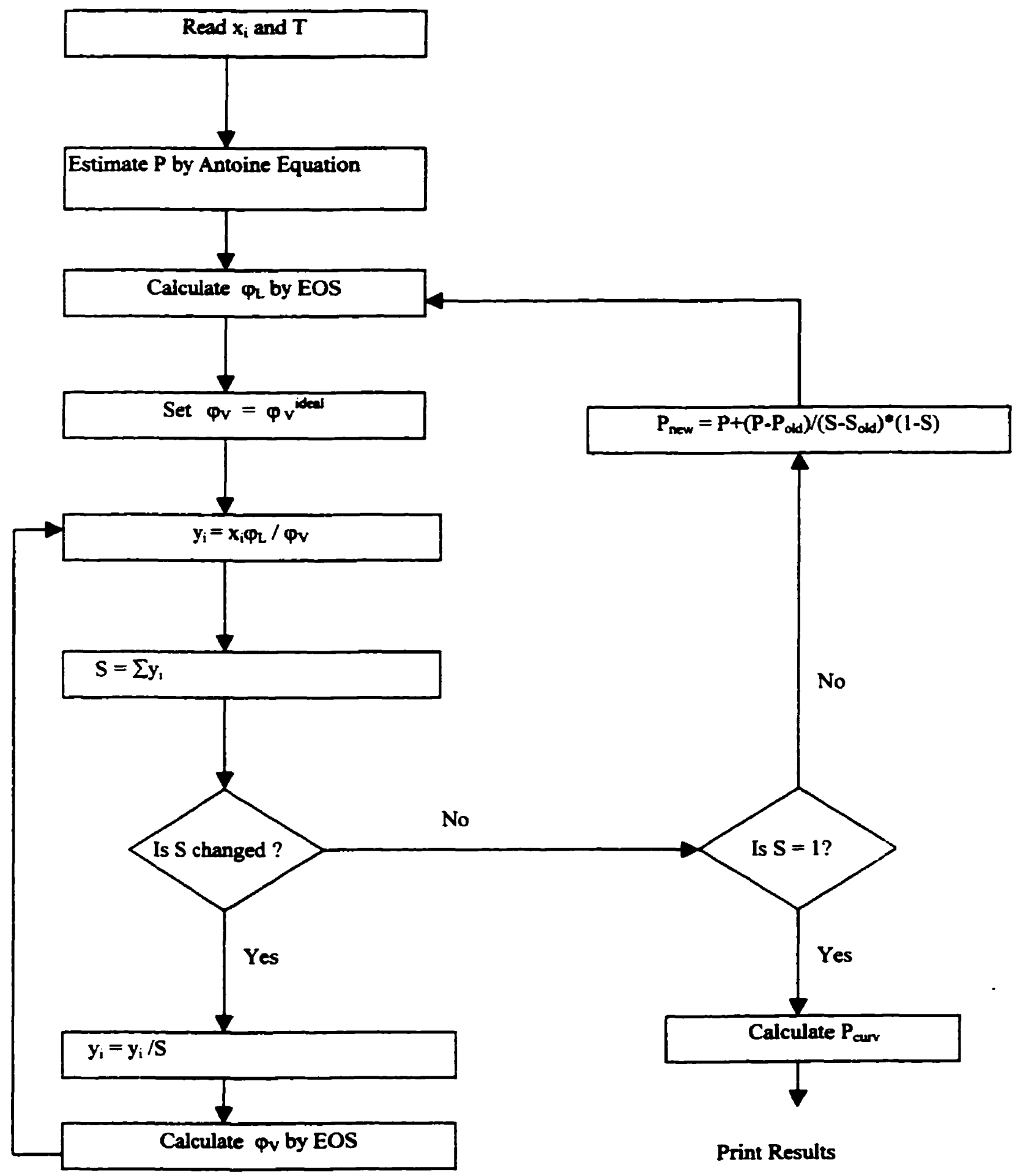


APPENDIX B: SS $_{\text {mod }}$ Model Program 
Program VLE (Output, OutVLE):

uses wincrt:

Const

$A I I=8.1122$;

$\mathrm{B} 11=1592.864 ;$

$C I I=226.184$;

A22 $=8.07131$;

$\mathrm{B} 22=1730.63$;

$C 22=233.426$;

$\mathrm{AI} 2 \mathrm{~W}=402.2349$;

$A 21 W=872.1894$;

$V I I=58.68$;

$v 12=18.07 ;$

$k I=2$;

$\mathrm{k} 2=-1$;

$\mathrm{R}=8.314$;

$\mathrm{T}=333.15$;

$\mathrm{TCI}=513.92$;

PCI $=6148$;

WCI $=0.64439$;

TC2 $=647.286$;

PC2 $=22089.75$;

wC2 $=0.3438$;

$k 11=-0.03374$;

$k 22=-0.06635$;

$k 12=-0.1268$;

$k 21=-0.0776$;

$112=-0.0$;

Var

xI, x2: Real;

$y 1, y 2:$ Real:

Pv1, Pv2:Real;

gama I, gama 2: Real;

Psat:Real;

Psystem, Pold, P1:Real:

PC:Real;

a1, b1: Real;

a2, b2:Real;

$a, b:$ Real;

avap, bvap: Real;

sigma 1, sigma 2:Real;

s1vapoI, s2vapor: Real;

k12bar:Real:

Vvapor,Vliquid:Real;

Zvapor, zliquid:Real:

philv, phi2v: Real:

phill, phi2L: Real;

VvSat, VISat:Real;

S, Sold, Stest:Real;

c, h: Real;

OUTVLE: Text ;

\{Antoine constants for ethanol\}
\{Antoine constants for water\}

\{Wilson parameters\}

\{molar volume of ethanol\}

\{molar volume of water\}

\{PRSV constant\}

\{PRSV constant\}

\{Gas constants, kpa.m^3/kmol.K\}

[System Temparature, K]

\{Critical properties of ethanol\}

\{Critical properties of water\}

\{12 denotes ethanol-water\}

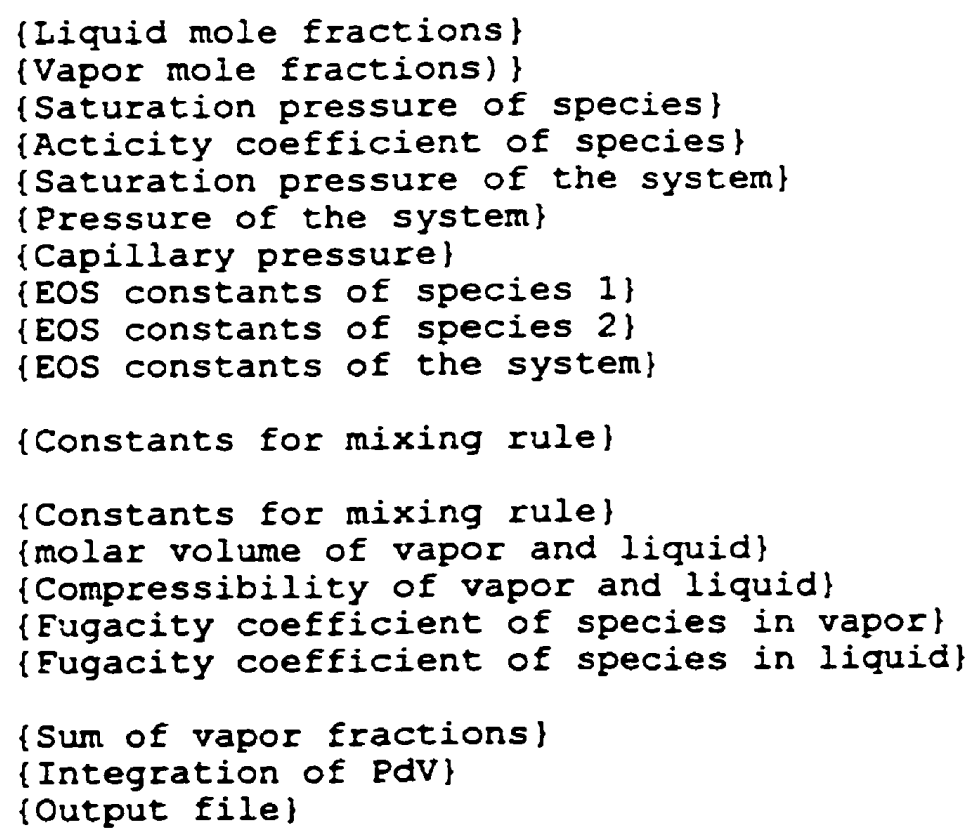

Procedure VaporPressure (var P1, P2:Real): \{P1,P2 in kPa\} 


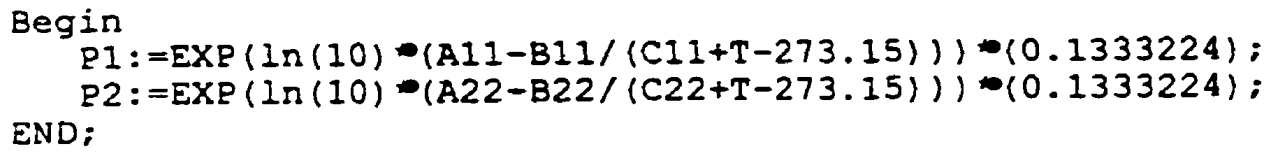

PROCEDURE ACtivityCoefficient (var r1,r2:Real):

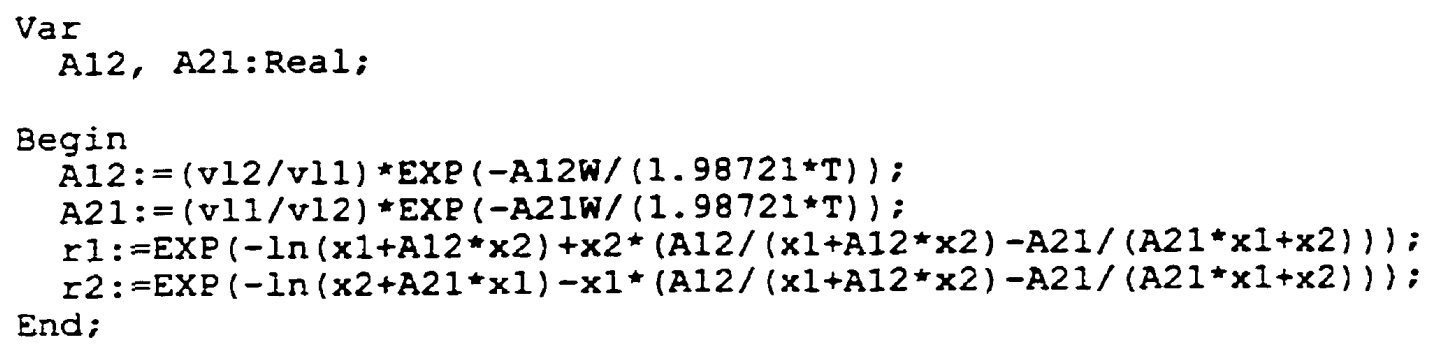


Root:Real;

M, N:Real;

phi:Real;

v1, v2, v3:Real;

value:Real;

Procedure ArcCos(var $x$, root:Real):

Begin

If $x>0.0$ Then root: =ArcTan (Sqrt $\left(1-x^{\star} x\right) / x$ )

End;

Else if $x<0.0$ Then root:=Arctan $\left(\operatorname{Sgrt}\left(1-x^{\star} x\right) / x\right)+p i$

Else root: $=p i / 2$

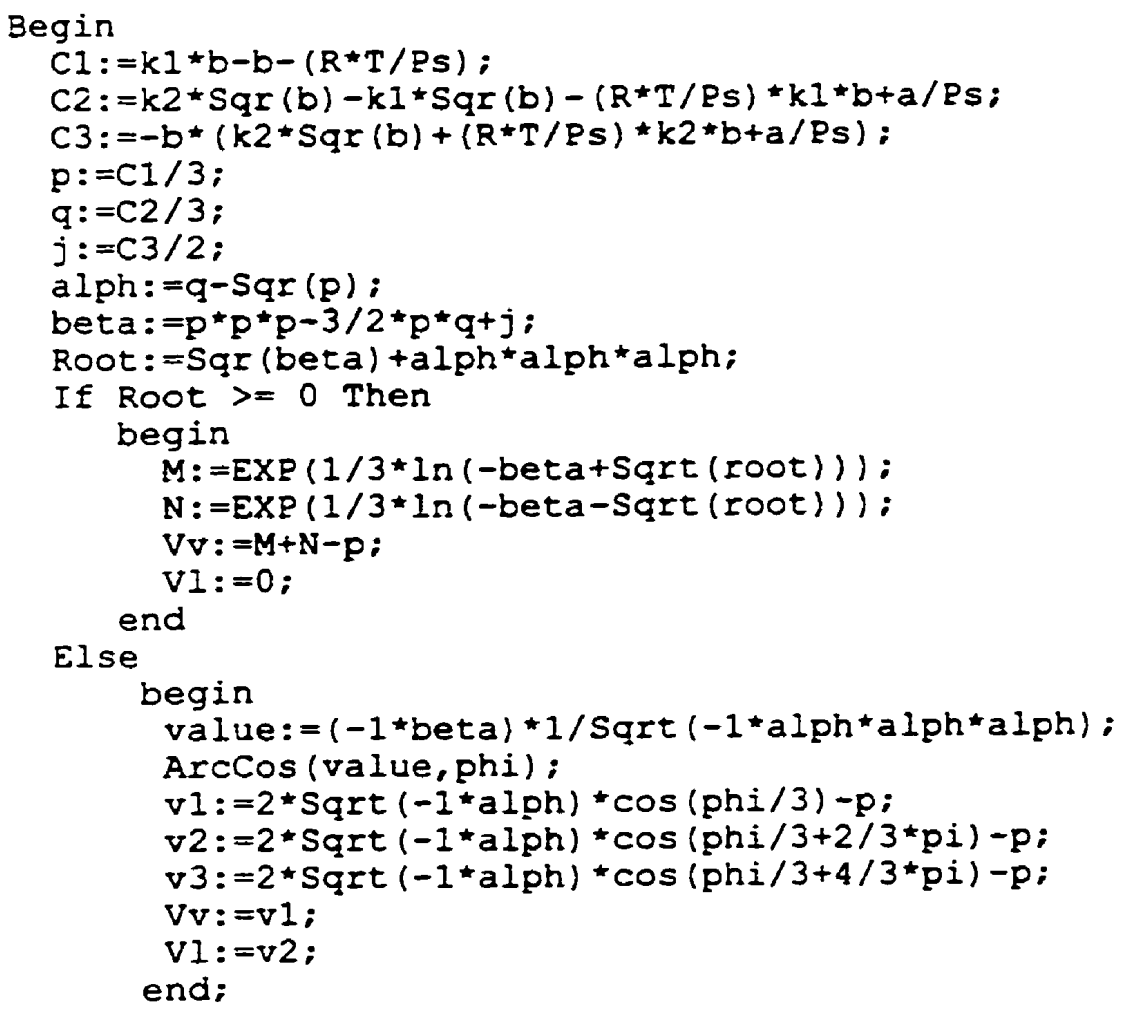

End;

Procedure CompressibilityCalculation (var V,z:Real):

Begin

End;

$$
z:=v /(v-b)-a \star v /(R \star T \star(v \star v+k 1 \star b \star v+k 2 \star \operatorname{Sqr}(b))) ;
$$

Procedure FugacityCalculation( $\operatorname{var}$ P,bi,z,sigma, phi:Real);

Var

Astar, Bstar : Real;

Begin

Astar: $=a \star P /(R \star R \star T \star T)$;

Bstar: $=b \star P /(R \star T)$;

phi: =EXP (bi/b*(z-1)-1n(z-Bstar)-Astar $(2 * \operatorname{Sqrt}(2) *$ Bstar $) *$

$($ sigma $-b i / b) \star \ln ((z+B s t a r *(1+\operatorname{Sgrt}(2))) /(2+$ Bstar*(1-Sqrt $(2)))))$; 
End;

Function $f(v o l: R e a l):$ Real:

Begin

$f:=R \star T /(\operatorname{vol}-b)-a /(\operatorname{Sqr}(v \circ l)+k 1 * v 01 * b+k 2 * \operatorname{Sqr}(b))$;

End:

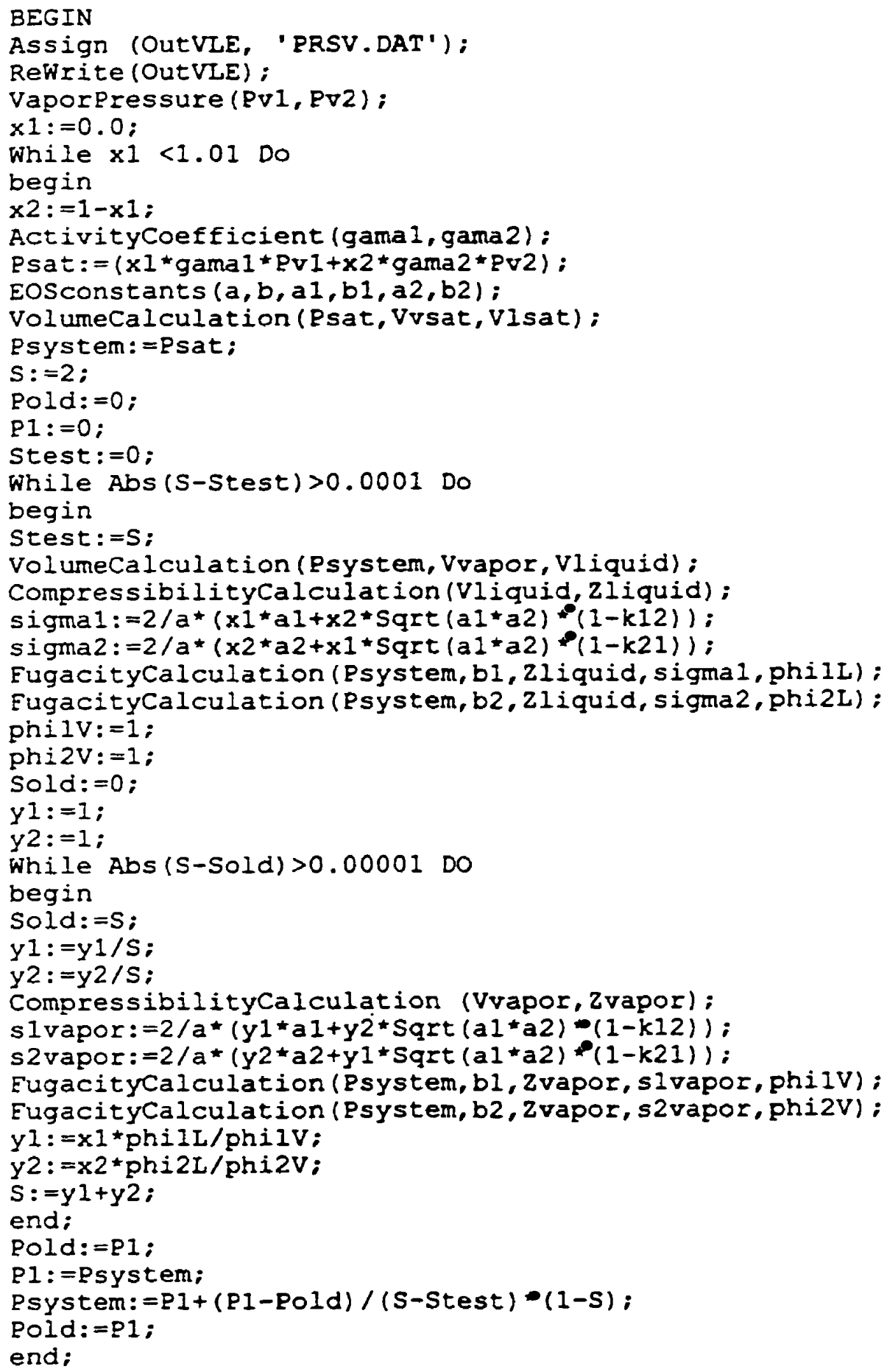


$\mathrm{h}:=1 / 4 *($ Vvsat-Vvapor) :

$C:=h / 3 *(f($ Vvapor $)+4 * f($ Vvapor $+h)+2 * f($ Vvapor $+2 * h)+4 * f($ Vvapor $+3 * h)+$ $f($ Vvaport4*h)):

PC: $=1 /$ Vliquid (Psat*Vvsat-Psystem *Vvapor-C-Vliquid* (Psat-Psystem)): $\times 1:=x 1+0.1$

end;

END. 
APPENDIX C: Vapor Phase Analyses by Two Different Methods 
Table C.1: Vapor Mole Fractions of Methanol Calculated by Two Different Methods ( $\mathrm{x}_{\mathrm{MeOH}}: 50 \%$ in isopropanol, $\mathrm{T}: 55^{\circ} \mathrm{C}$ )

\begin{tabular}{|l|c|c|c|}
\hline & $\begin{array}{l}\text { Peak area of } \\
\text { Methanol }\end{array}$ & $\begin{array}{l}\text { YMeOH using calibration } \\
\text { from literature }\end{array}$ & $\begin{array}{l}\text { YMeOH using } \\
\text { K factor }\end{array}$ \\
\hline Control & 73404 & 0.6514 & 0.6514 \\
\hline Sintered metal plate $(10 \mu \mathrm{m})$ & 76931 & $0.6827(4.8 \%$ increase $)$ & 0.6651 \\
\hline Sintered metal plate $(3 \mu \mathrm{m})$ & 79838 & $0.7087(8.7 \%$ increase $)$ & 0.6519 \\
\hline Fritted glass plate $(4-8 \mu \mathrm{m})$ & 77849 & $0.6911(6.1 \%$ increase) & 0.6521 \\
& 78895 & $0.7003(7.5 \%$ increase) & 0.6607 \\
\hline
\end{tabular}

The measurements were conducted by loading the bulk solution into the space underneath the plates. $10 \mathrm{~mL}$ of bulk solution loaded to the modified without porous media was used as control. The liquid level was adjusted after heating as in Judy Wong's experiments.

Table C.2: Vapor Mole Fractions of Ethanol Calculated by Two Different Methods ( $\mathrm{x}_{\text {EroH }}: 73 \%$ in n-octane, $\mathrm{T}: 75^{\circ} \mathrm{C}$ )

\begin{tabular}{|c|c|c|c|}
\hline & $\begin{array}{l}\text { Peak area of } \\
\text { Methanol }\end{array}$ & $\begin{array}{l}\text { YEoH using calibration } \\
\text { from literature }\end{array}$ & $\begin{array}{l}y_{\text {E⿺辶 }} \text { using } \mathbf{K} \\
\text { factor }\end{array}$ \\
\hline Control & 352511 & 0.8921 & 0.8921 \\
\hline \multirow[t]{3}{*}{ Fritted glass plate $(4-8 \mu \mathrm{m})$} & 386486 & 0.9780 (9.6\% increase) & 0.8940 \\
\hline & 366954 & $0.9286(4.1 \%$ increase $)$ & 0.8949 \\
\hline & 377261 & $0.9547(7.0 \%$ increase $)$ & 0.8888 \\
\hline
\end{tabular}

The measurements were conducted by pipetting $0.4 \mathrm{~mL}$ of bulk solution onto glass plates in each vial. $0.4 \mathrm{~mL}$ of bulk solution pipetted into the modified vial without porous media was used as control. 
APPENDIX D: Experimental Data 
Minimum Equilibrium Time for Methanol-Isopropanol ( $\mathrm{X}_{\text {моОн }}: 60 \%$ ): Figure 3.7

\begin{tabular}{|c|c|c|c|c|c|c|}
\hline \multirow[t]{2}{*}{ Time } & \multicolumn{2}{|c|}{ Peak Area } & \multicolumn{2}{|c|}{ Vapor Mol Fraction } & \multirow[b]{2}{*}{ average } & \multirow[b]{2}{*}{ Std.Dev } \\
\hline & Methanol & Isopropan & Methanol & Isopropan & & \\
\hline \multirow[t]{3}{*}{150} & $\overline{121810}$ & 83919 & 0.788 & 0.212 & & \\
\hline & $\begin{array}{l}120451 \\
129209\end{array}$ & $\begin{array}{l}83894 \\
95611\end{array}$ & $\begin{array}{l}0.786 \\
0.776\end{array}$ & $\begin{array}{l}0.214 \\
0.224\end{array}$ & & \\
\hline & 127741 & 91226 & 0.782 & 0.218 & 0.783 & 0.005 \\
\hline \multirow[t]{4}{*}{300} & 130622 & 98788 & 0.772 & 0.228 & & \\
\hline & 129000 & 94713 & 0.777 & 0.223 & & \\
\hline & 127946 & 92596 & 0.780 & 0.220 & & \\
\hline & 125934 & 84626 & 0.792 & 0.208 & 0.781 & 0.00854 \\
\hline \multirow[t]{4}{*}{450} & 129002 & 95812 & 0.775 & 0.225 & & \\
\hline & 129746 & 94497 & 0.779 & 0.221 & & \\
\hline & 129384 & 31917 & 0.783 & 0.217 & & \\
\hline & 127782 & 92628 & 0.780 & 0.220 & 0.779 & 0.00314 \\
\hline \multirow[t]{2}{*}{750} & $\begin{array}{l}129837 \\
130974\end{array}$ & $\begin{array}{l}95070 \\
95874\end{array}$ & $\begin{array}{l}0.778 \\
0777\end{array}$ & 0.222 & 0778 & \\
\hline & & & 0.777 & 0.223 & 0.178 & \\
\hline
\end{tabular}

$K$ constant for methanol: Figure 3.8

\begin{tabular}{|c|c|c|}
\hline $\begin{array}{c}\text { moles of MeOH } \\
\text { injected to GC } \\
\text { (nmol) }\end{array}$ & \multicolumn{2}{|c|}{ K(nmol/peak area) } \\
\cline { 2 - 3 } & average & stdev \\
\hline 0.0148 & 5.13055 & 0.12283 \\
0.0247 & 5.33518 & 0.05074 \\
0.0345 & 5.52650 & 0.01943 \\
0.0468 & 5.58355 & 0.03140 \\
0.0935 & 5.54829 & 0.01741 \\
\hline
\end{tabular}

1uL of diluted liquid sample was injected to the GC using syringe at column temperature of $95 \mathrm{C}$

Methanol-Isopropanol Mixtures w/o Porous Media (55C): Figure 3.9

\begin{tabular}{|c|c|c|c|}
\hline$X$ mtoh & y literat & y experi & stdev \\
\hline \hline 0 & 0 & 0 & 0 \\
0.0595 & 0.1282 & 0.12301 & 0.00110 \\
0.2021 & 0.362 & 0.33354 & 0.00051 \\
0.322 & 0.5166 & 0.49557 & 0.00028 \\
0.3877 & 0.5895 & 0.57332 & 0.00072 \\
0.4871 & 0.684 & 0.67939 & 0.00040 \\
0.6031 & 0.7727 & 0.77709 & 0.00044 \\
0.7169 & 0.845 & 0.85709 & 0.00097 \\
0.7916 & 0.8898 & 0.90409 & 0.00094 \\
0.9193 & 0.9643 & 0.96844 & 0.00103 \\
1 & 1 & 1 & 0 \\
\hline
\end{tabular}

Measured by loading $10 \mathrm{~mL}$ of mixtures into unmodified vials with equilibrium time of $750 \mathrm{~min}$ 


\begin{tabular}{|r|r|l|}
\hline \multicolumn{1}{|c|}{$X_{\text {EtOH }}$} & y experi & stdev \\
\hline \hline 0.182 & 0.7755 & 0.00036 \\
0.3574 & 0.8014 & 0.00518 \\
0.481 & 0.8106 & 0.00109 \\
0.5816 & 0.8177 & 0.00007 \\
0.6496 & 0.8224 & 0.00043 \\
0.7355 & 0.8292 & 0.00014 \\
0.8066 & 0.8381 & 0.00033 \\
0.893 & 0.8612 & 0.00074 \\
0.957 & 0.9145 & 0.00526 \\
\hline
\end{tabular}

Measured by loading $10 \mathrm{~mL}$ of mixtures into unmodified vials with equilibrium time of $750 \mathrm{~min}$

Calibration Curve for Ethanol-Water at 60C: Figure 3.11

\begin{tabular}{|c|c|c|c|c|c|c|c|c|}
\hline \multirow[t]{2}{*}{ Liq.frac. } & \multicolumn{8}{|c|}{ Equilibrium Time (min) :Peak Area } \\
\hline & \multicolumn{4}{|c|}{250} & \multicolumn{4}{|c|}{350} \\
\hline$\overline{0}$ & $\overline{\overline{0}}$ & $\overline{0}$ & 0 & $\overline{0}$ & 0 & 0 & & \\
\hline 0.2 & 136165 & 136521 & 136204 & 138543 & 135882 & 136382 & 13 & 374 \\
\hline 0.4 & 164126 & 166651 & 167424 & 164341 & 166698 & 164937 & 16 & \\
\hline 0.6 & 187521 & 184153 & 190051 & 187873 & 188383 & 187115 & & \\
\hline $\begin{array}{c}0.8 \\
1\end{array}$ & $\begin{array}{l}224747 \\
269805\end{array}$ & $\begin{array}{l}232728 \\
275560\end{array}$ & $\begin{array}{l}227526 \\
275604\end{array}$ & $\begin{array}{l}224546 \\
267551\end{array}$ & $\begin{array}{l}225544 \\
273645\end{array}$ & $\begin{array}{l}224654 \\
277243\end{array}$ & $\begin{array}{l}225521 \\
274503\end{array}$ & $\begin{array}{l}218259 \\
271331\end{array}$ \\
\hline
\end{tabular}

Measured by loading $10 \mathrm{~mL}$ of mixtures into unmodified vials with Sul sampl loop 


\section{VLE with Porous Media}

Ethanol-Water Mixtures (60C)

Shin's Experiment (40um sintered metal) : Figure 4.10

\begin{tabular}{|c|c|}
\hline$X_{\text {ETOH }}$ & $Y_{\text {ETOH }}$ \\
\hline 0.2 & 0.4858 \\
0.4 & 0.5797 \\
0.6 & 0.6973 \\
0.85 & 0.8678 \\
\hline
\end{tabular}

Meausred by loading the liquid underneath the plate and adjust the liquid level as in Wong's experiment

Wong's Experiment (5um fritted glass): Figure 4.11

\begin{tabular}{|c|c|}
\hline$X_{\text {E:OH }}$ & $Y_{\text {EROH }}$ \\
\hline \hline 0.2 & 0.51 \\
0.3 & 0.55 \\
0.5 & 0.653 \\
0.6 & 0.725 \\
0.7 & 0.77 \\
0.89 & 0.93 \\
0.9697 & 0.97 \\
\hline
\end{tabular}

Meausred by loading the liquid underneath the plate and adjust the liquid level

\section{Propanol-Water Mixtures (60C)}

Wong's Experiment (5um fritted glass): Figure 4.12

\begin{tabular}{|c|c|}
\hline$X_{\text {propenol }}$ & $Y_{\text {propenal }}$ \\
\hline \hline 0.3 & 0.444 \\
0.3999 & 0.45 \\
0.4 & 0.449 \\
0.6915 & 0.532 \\
0.7 & 0.526 \\
0.8494 & 0.669 \\
\hline
\end{tabular}

Meausred by loading the liquid underneath the plate and adjust the liquid level

\section{Methanol-Isopropanol Mixtures (55C)}

Shin's Experiment (5um fritted glass): Figure 4.13

\begin{tabular}{|l|l|}
\hline$X_{\text {MeOH }}$ & $Y_{\text {MOOH }}$ \\
\hline \hline 0.1902 & 0.3428 \\
0.4682 & 0.6664 \\
0.5990 & 0.7693 \\
0.7946 & 0.8915 \\
0.8854 & 0.9479 \\
\hline
\end{tabular}

Meausred by loading $0.4 \mathrm{~mL}$ of liquid directly onto the plate 


\section{Ethanol-n-Octane Mixtures (75C)}

Shin's Experiment (5um fritted glass): Figure 4.14

\begin{tabular}{|c|c|}
\hline$X_{\text {EIOH }}$ & $Y_{\text {EEOH }}$ \\
\hline \hline 0.182 & 0.7755 \\
0.3574 & 0.8014 \\
0.5816 & 0.8177 \\
0.6496 & 0.8224 \\
0.8066 & 0.8381 \\
0.893 & 0.8612 \\
\hline
\end{tabular}

Meausred by loading $0.4 \mathrm{~mL}$ of liquid directly onto the plate

\section{Additional Information Not Appeared in the Text}

This test was conducted to check any absorption of compounds through the rubber septa. $0.4 \mathrm{~mL}$ of solution was pipetted into the vials. The wrapped vials indicate that the bottom septa were wrapped with aluminum foil. The modified vials were used as control and the vials with the plates were conditioned exactly the same as the control (either wrapped or unwrapped depending on the control)

\section{Liquid: Ethanol-n-Octane at $75 \mathrm{C}$}
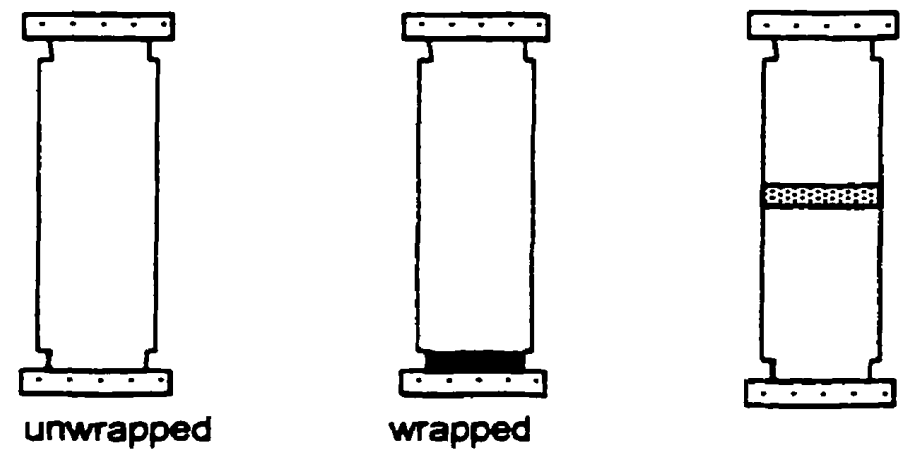

\begin{tabular}{|c|c|c|c|}
\hline $\begin{array}{c}X_{E R O H} \\
18 \mathrm{~mol} \% \\
\end{array}$ & 0.607 & & 0.616 \\
\hline $27 \mathrm{~mol} \%$ & 0.723 & & 0.711 \\
\hline 36 mole $\%$ & & 0.768 & 0.760 \\
\hline $48 \mathrm{~mole} \%$ & 0.825 & & 0.817 \\
\hline 73 mole $\%$ & 0.887 & 0.892 & $\begin{array}{l}0.895 \\
0.893 \\
\end{array}$ \\
\hline 89 mole\% & 0.938 & 0.938 & $\begin{array}{l}0.937 \\
0.936\end{array}$ \\
\hline
\end{tabular}




\section{VLE Predicted by the Model}

Ethanol-Water Mixtures (60C): Figure 4.2

\begin{tabular}{|c|c|c|c|c|}
\hline & & \multicolumn{3}{|c|}{ v predicted } \\
\cline { 3 - 5 }$x_{\text {froH }}$ & y literature & 40 micron & 100 micror 5 micron \\
\hline 0.01 & 0.102 & 0.1138 & 0.1067 & 0.1965 \\
0.03 & 0.227 & 0.2506 & 0.2364 & 0.4156 \\
0.05 & 0.302 & 0.3304 & 0.3134 & 0.5293 \\
0.08 & 0.369 & 0.3996 & 0.3812 & 0.6135 \\
0.1 & 0.399 & 0.4287 & 0.4109 & 0.6370 \\
0.15 & 0.449 & 0.4778 & 0.4605 & 0.6797 \\
0.2 & 0.481 & 0.5084 & 0.4919 & 0.7050 \\
0.25 & 0.506 & 0.5324 & 0.5165 & 0.7250 \\
0.3 & 0.529 & 0.5547 & 0.5393 & 0.7450 \\
0.4 & 0.574 & 0.5995 & 0.5842 & 0.7850 \\
0.5 & 0.622 & 0.6474 & 0.6322 & 0.8300 \\
0.6 & 0.677 & 0.7020 & 0.6870 & 0.8700 \\
0.7 & 0.74 & 0.7646 & 0.7500 & 0.9100 \\
0.8 & 0.814 & 0.8384 & 0.8241 & 0.9450 \\
0.85 & 0.855 & 0.8790 & 0.8647 & 0.9600 \\
0.86 & 0.864 & 0.8878 & 0.8730 & 0.9650 \\
0.87 & 0.872 & 0.8957 & 0.8803 & 0.9700 \\
0.88 & 0.881 & 0.9046 & 0.8887 & 0.9730 \\
0.89 & 0.8902 & 0.9138 & 0.8973 & 0.9780 \\
0.895 & 0.8948 & 0.9183 & 0.9014 & 0.9790 \\
0.9 & 0.899 & 0.9225 & 0.9051 & 0.9800 \\
0.91 & 0.909 & 0.9325 & 0.9146 & 0.9810 \\
0.92 & 0.918 & 0.9415 & 0.9232 & 0.9820 \\
0.93 & 0.928 & 0.9515 & 0.9328 & 0.9870 \\
1 & 1 & 1.0000 & 1.0000 & 1.0000 \\
\hline & & & & \\
\hline
\end{tabular}

Propanol-Water Mixtures (60C): Figure 4.3

\begin{tabular}{|c|c|c|c|c|}
\hline & & \multicolumn{3}{|c|}{ y predicted } \\
\cline { 2 - 5 }$x_{\text {rromed }}$ & y literature & 100 micror & 40 micron & 5 micron \\
\hline \hline 0.025 & 0.273 & 0.2872 & 0.3086 & 0.5580 \\
0.05 & 0.34 & 0.3574 & 0.3836 & 0.6889 \\
0.1 & 0.385 & 0.4044 & 0.4336 & 0.7550 \\
0.2 & 0.404 & 0.4237 & 0.4532 & 0.7850 \\
0.3 & 0.41 & 0.4292 & 0.4580 & 0.7942 \\
0.4 & 0.422 & 0.4411 & 0.4697 & 0.8000 \\
0.5 & 0.438 & 0.4572 & 0.4859 & 0.8000 \\
0.6 & 0.463 & 0.4830 & 0.5131 & 0.8000 \\
0.7 & 0.506 & 0.5275 & 0.5598 & 0.8014 \\
0.8 & 0.583 & 0.6097 & 0.6497 & 0.8250 \\
0.9 & 0.72 & 0.7528 & 0.8020 & 0.9000 \\
0.95 & 0.83 & 0.8672 & 0.9000 & 0.9511 \\
0.975 & 0.905 & 0.9227 & 0.9492 & 0.9800 \\
\hline
\end{tabular}


Methanol-Isopropanol Mixtures (55C): Figure 4.4

\begin{tabular}{|r|r|c|c|c|}
\hline & & \multicolumn{3}{|c|}{$y$ predicted } \\
\cline { 2 - 5 }$x_{\text {my }}$ & v literature & \multicolumn{1}{|c|}{100} & \multicolumn{1}{|c|}{40} & \multicolumn{1}{|c|}{5} \\
\hline 0.0451 & 0.112 & 0.1128 & 0.1141 & 0.1290 \\
0.0822 & 0.1702 & 0.1715 & 0.1735 & 0.1947 \\
0.1069 & 0.2056 & 0.2071 & 0.2095 & 0.2337 \\
0.1638 & 0.3062 & 0.3085 & 0.3119 & 0.3457 \\
0.1902 & 0.3428 & 0.3452 & 0.3489 & 0.3844 \\
0.2107 & 0.3711 & 0.3738 & 0.3778 & 0.4133 \\
0.2314 & 0.407 & 0.4099 & 0.4142 & 0.4502 \\
0.2739 & 0.4626 & 0.4658 & 0.4706 & 0.5082 \\
0.3498 & 0.546 & 0.5497 & 0.5553 & 0.5957 \\
0.3986 & 0.6027 & 0.6067 & 0.6127 & 0.6530 \\
0.4682 & 0.6664 & 0.6708 & 0.6773 & 0.7170 \\
0.531 & 0.7189 & 0.7235 & 0.7305 & 0.7680 \\
0.599 & 0.7693 & 0.7742 & 0.7815 & 0.8160 \\
0.6983 & 0.833 & 0.8381 & 0.8458 & 0.8772 \\
0.7372 & 0.8596 & 0.8648 & 0.8727 & 0.8987 \\
0.7946 & 0.8915 & 0.8969 & 0.9050 & 0.9253 \\
0.8432 & 0.9191 & 0.9247 & 0.9331 & 0.9470 \\
0.8854 & 0.9479 & 0.9536 & 0.9623 & 0.9695 \\
0.9232 & 0.9636 & 0.9694 & 0.9781 & 0.9782 \\
0.9529 & 0.9816 & 0.9875 & 0.9964 & 0.9890 \\
\hline
\end{tabular}

Ethanol-n-Octane Mixtures (75C): Figure 4.5

\begin{tabular}{|c|c|c|c|c|}
\hline$X_{\text {EtOH }}$ & $y$ literature & \multicolumn{3}{|c|}{$y$ predicted } \\
\cline { 3 - 5 } & & 100 & 40 & 5 \\
\hline \hline 0.0033 & 0.1907 & 0.1931 & 0.1966 & 0.2409 \\
0.0103 & 0.3379 & 0.3413 & 0.3465 & 0.4108 \\
0.03 & 0.6054 & 0.6092 & 0.6148 & 0.6846 \\
0.0659 & 0.7178 & 0.7210 & 0.7258 & 0.7857 \\
0.1585 & 0.7762 & 0.7790 & 0.7832 & 0.8351 \\
0.229 & 0.7867 & 0.7894 & 0.7934 & 0.8430 \\
0.3022 & 0.7993 & 0.8019 & 0.8058 & 0.8541 \\
0.477 & 0.8126 & 0.8151 & 0.8188 & 0.8647 \\
0.5557 & 0.8167 & 0.8191 & 0.8228 & 0.8679 \\
0.6558 & 0.8224 & 0.8248 & 0.8284 & 0.8725 \\
0.7163 & 0.8303 & 0.8327 & 0.8362 & 0.8755 \\
0.789 & 0.8409 & 0.8432 & 0.8468 & 0.8812 \\
0.8639 & 0.8589 & 0.8613 & 0.8648 & 0.8945 \\
0.8909 & 0.8712 & 0.8736 & 0.8772 & 0.9017 \\
0.9245 & 0.8916 & 0.8940 & 0.8977 & 0.9170 \\
0.9292 & 0.8946 & 0.8970 & 0.9007 & 0.9144 \\
0.9721 & 0.943 & 0.9456 & 0.9496 & 0.9578 \\
0.9832 & 0.96 & 0.9627 & 0.9667 & 0.9689 \\
\hline
\end{tabular}

